This document is available under a CC-BY-NC-ND license. 


\section{Thermodynamic Study for Micellization of Imidazolium Based Surface Active Ionic Liquids in Water: Effect of Alkyl Chain Length and Anions}

Bojan Šarac ${ }^{\mathrm{a}}, \check{Z ̌ i g a ~ M e d o s ̌ ~}^{\mathrm{a}}$, Alice Cognigni ${ }^{\mathrm{b}}$, Katharina Bica ${ }^{\mathrm{b}, *}$, Li-Jen Chen ${ }^{\mathrm{c}}$, Marija BešterRogač $\check{a}^{\mathrm{a}} *$

${ }^{a}$ Faculty of Chemistry and Chemical Technology, University of Ljubljana, Večna pot 113, SI-1000 Ljubljana, Slovenia

${ }^{\mathrm{b}}$ Institute of Applied Synthetic Chemistry, Vienna University of Technology Getreidemarkt 9/163, A-1060 Vienna, Austria

'Department of Chemical Engineering, National Taiwan University, Taipei 10617, Taiwan

*Corresponding authors:

Katharina Bica

Institute of Applied Synthetic Chemistry, Vienna University of Technology Getreidemarkt 9/163 A-1060 Vienna, Austria

katharina.schroeder@tuwien.ac.at

Marija Bešter-Rogač

Faculty of Chemistry and Chemical Technology, Večna pot 113, University of Ljubljana, SI1000 Ljubljana, Slovenia

marija.bester@fkkt.uni-lj.si 


\section{Abstract}

A systematic investigation of influence of the length of the side alkyl chain and the counter ions on the thermodynamic of the micellization process at imidazolium based surface active ionic liquids (SAILs) in aqueous solution was carried out by isothermal titration calorimetry (ITC) in a broad temperature range.

The effect of alkyl chain length on the micellization process in water has been investigated on 1decyl-3-methylimidazolium $\left(\left[\mathrm{C}_{10} \mathrm{mim}\right] \mathrm{Cl}\right)$ 1-dodecyl-3-methylimidazolium $\left(\left[\mathrm{C}_{12} \mathrm{mim}\right] \mathrm{Cl}\right), 1$ tetradecyl-3-methylimidazolium $\left(\left[\mathrm{C}_{14} \mathrm{mim}\right] \mathrm{Cl}\right)$ and 1-hexadecyl-3-methylimidazolium $\left(\left[\mathrm{C}_{16} \mathrm{mim}\right] \mathrm{Cl}\right)$ chlorides, whereas the influence of counterion was studied at the micellization of 1-dodecyl-3-methylimidazolium chloride $\left(\left[\mathrm{C}_{12} \mathrm{mim}\right] \mathrm{Cl}\right)$, bromide $\left(\left[\mathrm{C}_{12} \mathrm{mim}\right] \mathrm{Br}\right)$, iodide $\left(\left[\mathrm{C}_{12} \mathrm{mim}\right] \mathrm{I}\right)$, acetate $\left(\left[\mathrm{C}_{12} \mathrm{mim}\right] \mathrm{OAc}\right)$, methanesulfonate $\left(\left[\mathrm{C}_{12} \mathrm{mim}\right] \mathrm{OMs}\right)$, toluensulfonate ( ([C $\left.\left.\mathrm{C}_{12} \mathrm{mim}\right] \mathrm{OTs}\right)$, trifluromethane sulfonate $\left(\left[\mathrm{C}_{12} \mathrm{mim}\right] \mathrm{OTf}\right)$, trifluoro acetate $\left(\left(\left[\mathrm{C}_{12} \mathrm{mim}\right] \mathrm{TFA}\right)\right.$ and salicylate $\left(\left[\mathrm{C}_{12} \mathrm{mim}\right] \mathrm{Sal}\right)$ in water.

From ITC experimental data, the corresponding standard thermodynamic parameters of micellization (enthalpy, $\Delta_{\mathrm{M}} H^{0}$; Gibbs free energy, $\Delta_{\mathrm{M}} G^{0}$; entropy, $\Delta_{\mathrm{M}} S^{0}$; heat capacity change, $\Delta_{\mathrm{M}} c_{p}^{0}$ ) were estimated by help of the mass-action model. It was found that SAILs behave mainly like common cationic surfactant, where cmc values are decreasing with the length of the side alkyl chain and exhibit U-shape dependence on temperature. Remarkable influence of counter ions on cmc and all thermodynamic functions was observed, however the entropyenthalpy compensation turned out as the fact, arising from the from the relationship $\Delta G=\Delta H-$

$T \Delta S . \Delta_{\mathrm{M}} c_{p}^{0}$ values were further discussed in terms of the removal of solvent accessible surface areas of SAILs and counterion from the contact with water after micellization.

Key words: surface active imidazolium based ionic liquids, micellization, isothermal titration calorimetry, thermodynamic study, solvent accessible surface area 


\section{Introduction}

Ionic liquids have recently attracted much attention as new class of surfactants. It has in fact been demonstrated that ionic liquids containing long alkyl chains behave similar to conventional surfactants forming aggregates in water [1]. Several structures have been investigated changing alkyl chain length, charged head group structure, functional groups, both cationic and anionic surface active ionic liquids have been described $[2,3,4,5,6,7,8]$. An attractive factor for continuous research in this field is that these ionic liquids have generally been found to have a superior surface activity in comparison to corresponding alkyltrimethylammonium based surfactants, or corresponding anionic surfactants with inorganic cations [9]. Moreover the high tunability of ionic liquids opens up a broad range of applications for surface active ionic liquids (SAILs), such as in micellar catalysis or in separation processes $[10,11,12]$.

There are already some studies dealing with thermodynamic properties of imidazolium-based SAILs in the literature $[13,14,15]$ investigating quite narrow selections of anions $\left(\mathrm{Cl}^{-}, \mathrm{Br}^{-}\right)$.

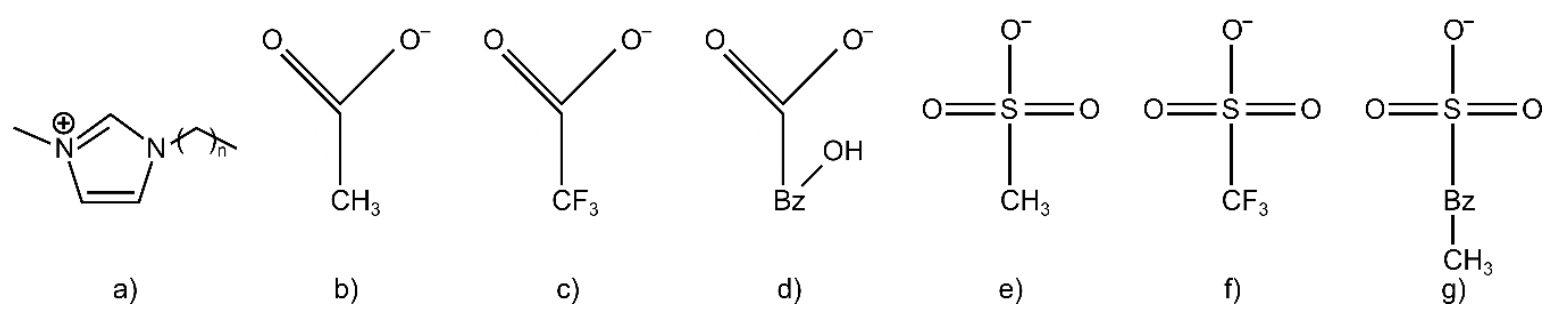

Scheme 1. Structures of investigated systems: a) $n=9\left(\left[\mathrm{C}_{10} \mathrm{mim}\right]\right), \mathrm{n}=11\left(\left[\mathrm{C}_{12} \mathrm{mim}\right]\right), \mathrm{n}=13$ $\left(\left[\mathrm{C}_{14} \mathrm{mim}\right]\right)$ and $\mathrm{n}=15\left(\left[\mathrm{C}_{16} \mathrm{mim}\right]\right)$ cations in $\left(\left[\mathrm{C}_{X} \mathrm{mim}\right] \mathrm{Cl}\right)$ and b) OAc, c) TFA, d) Sal, e) OMs, f) OTf, and g) OTs anions in $\left[\mathrm{C}_{12} \mathrm{mim}\right] \mathrm{X}$ systems.

Thus we decided to carry out a systematic thermodynamic investigation of influence of the length of the side alkyl chain and the counter ions on the micellization process of imidazolium based SAILs in aqueous solution by isothermal titration calorimetry (ITC) as one of the most valuable techniques for thermodynamic analysis. 
ITC experiments were performed within the temperature range of 278.15 to $318.15 \mathrm{~K}$ in $10 \mathrm{~K}$ steps on 1-decyl-3-methylimidazolium $\left(\left[\mathrm{C}_{10} \mathrm{mim}\right] \mathrm{Cl}\right)$ 1-dodecyl-3-methylimidazolium $\left(\left[\mathrm{C}_{12} \mathrm{mim}\right] \mathrm{Cl}\right)$, 1-tetradecyl-3-methylimidazolium $\left(\left[\mathrm{C}_{14} \mathrm{mim}\right] \mathrm{Cl}\right)$ and 1-hexadecyl-3methylimidazolium $\left(\left[\mathrm{C}_{16} \mathrm{mim}\right] \mathrm{Cl}\right)$ chlorides. To obtain more information about the influence of counterion on the micellization, measurements were carried out also for 1-dodecyl-3methylimidazolium bromide $\left(\left[\mathrm{C}_{12} \mathrm{mim}\right] \mathrm{Br}\right)$, iodide $\left(\left[\mathrm{C}_{12} \mathrm{mim}\right] \mathrm{I}\right)$, acetate $\left(\left[\mathrm{C}_{12} \mathrm{mim}\right] \mathrm{OAc}\right)$, methanesulfonate $\left(\left[\mathrm{C}_{12} \mathrm{mim}\right] \mathrm{OMs}\right)$, toluensulfonate (tosylate, $\left(\left[\mathrm{C}_{12} \mathrm{mim}\right] \mathrm{OTs}\right)$, trifluromethane sulfonate $\left(\left[\mathrm{C}_{12} \mathrm{mim}\right] \mathrm{OTf}\right)$, trifluoro acetate $\left(\left(\left[\mathrm{C}_{12} \mathrm{mim}\right] \mathrm{TFA}\right)\right.$ and salicylate $\left(\left[\mathrm{C}_{12} \mathrm{mim}\right] \mathrm{Sal}\right)$. The structures of investigated SAILs and anions are presented on Scheme 1. The corresponding standard thermodynamic parameters of micellization (enthalpy, $\Delta_{\mathrm{M}} H^{0}$; Gibbs free energy, $\Delta_{\mathrm{M}} G^{0}$; entropy, $\Delta_{\mathrm{M}} S^{0}$; heat capacity change, $\Delta_{\mathrm{M}} c_{p}^{0}$ ) were estimated by fitting of the model equation based on the mass-action model to the experimental data. EEC effect was discussed in terms of the side alkyl chain length and the effect of counter ions on EEC was presented. In addition, $\Delta_{\mathrm{M}} c_{p}^{0}$ was further correlated to the changes in solvent accessible surface upon micelle formation. 


\section{Experimental Section}

\section{Materials}

Commercially available reagents and solvents were used as received from Sigma Aldrich unless otherwise specified. Deionized water was obtained from a Millipore Milli-Q water purification system (Millipore, USA). ${ }^{1} \mathrm{H}$ and ${ }^{13} \mathrm{C}$ NMR spectra were recorded on a Bruker AC 200 at 200 $\mathrm{MHz}$, using the solvent peak as reference. All ionic liquids were dried for at least $48 \mathrm{~h}$ at room temperature and 0.01 mbar before use and were stored under argon atmosphere.

\section{Synthetic procedures}

\section{Synthesis of $\left[\mathrm{C}_{12}\right.$ mim $] \mathrm{X}, \mathrm{X}=\mathrm{Cl}, \mathrm{Br}, \mathrm{I}$}

The halide-based imidazolium salts were synthesized according to standard methodologies, which include the alkylation of $\mathrm{N}$-methylimidazole with the appropriate alkyl halide to afford the corresponding imidazolium halide. The ILs were repeatedly crystallized in order to obtain colorless solids. Detailed results are reported in our previous work [12].

\section{Synthesis of [ $\left.\mathrm{C}_{12} \mathrm{mim}\right] \mathrm{X}, \mathrm{X}=\mathrm{OMs}^{-}, \mathrm{OTs} \mathrm{s}^{-}, \mathrm{OTf}, \mathrm{TFA}^{-}$}

Surface-active ionic liquids $\left[\mathrm{C}_{12} \mathrm{mim}\right] \mathrm{OMs},\left[\mathrm{C}_{12} \mathrm{mim}\right] \mathrm{OTs}$, $\left[\mathrm{C}_{12} \mathrm{mim}\right] \mathrm{OTf}$ and $\left[\mathrm{C}_{12} \mathrm{mim}\right] \mathrm{TFA}$ were prepared in a two steps synthesis route, including the initial synthesis of $N$-dodecylimidazole by alkylation of imidazole. Afterwards the final ionic liquids were obtained via direct alkylation of $\mathrm{N}$-dodecylimidazole with the methyl esters of the corresponding anions. Detailed results are reported in our previous work [12].

\section{Synthesis of $\left[C_{12} \underline{\text { mim }] T F A}\right.$}

$\mathrm{N}$-dodecylimidazole $(1.31 \mathrm{~g}, 5.5 \mathrm{mmol})$ was dissolved in $5 \mathrm{~mL}$ anhydrous acetonitrile and freshly distilled methyl trifluoroaceticacid $(4.8 \mathrm{~g}, 3.8 \mathrm{ml}, 38 \mathrm{mmol})$ was added drop wise while cooling in an ice bath. The reaction mixture was then stirred for 7 days at $70^{\circ} \mathrm{C}$ until NMR showed complete conversion. The volatiles materials were removed under reduced pressure, and the product was repeatedly washed with $n$-hexane. 1-Dodecyl-3-methylimidazolium trifluoroacetate was obtained via filtration as pale solid in $98 \%$ yield. mp: $37.3^{\circ}$ C. $\mathrm{C}_{18} \mathrm{H}_{31} \mathrm{~F}_{3} \mathrm{~N}_{2} \mathrm{O}_{2}$ (464.45): calcd. C 59.32, H 8.57, N 7.69\%; found C 59.13, H 8.69, N 7.59. $v_{\max }\left(\mathrm{cm}^{-1}\right): 2918(\mathrm{C}-\mathrm{H}), 1679\left(\mathrm{CO}_{2}{ }^{-}\right)$, $1578(\mathrm{C}=\mathrm{C}), 1159(\mathrm{C}-\mathrm{N}), 1115(\mathrm{C}-\mathrm{F}) .{ }^{1} \mathrm{NMR}\left(200 \mathrm{MHz}, \mathrm{CDCl}_{3}\right): \delta(\mathrm{ppm})=0.81(3 \mathrm{H}, \mathrm{t}, \mathrm{J}=6.06$ 
$\left.\mathrm{Hz},-\mathrm{C}_{11} \mathrm{H}_{22}-\mathrm{CH}_{3}\right), 1.19\left(18 \mathrm{H}, \mathrm{m},-\mathrm{C}_{2} \mathrm{H}_{4}-\mathrm{C}_{9} \mathrm{H}_{18}-\mathrm{CH}_{3}\right), 1.80\left(2 \mathrm{H}\right.$, br, $\left.-\mathrm{CH}_{2}-\mathrm{CH}_{2}-\mathrm{C}_{10} \mathrm{H}_{21}\right), 3.94(3 \mathrm{H}$, s, N-CH $\left.H_{3}\right), 4.15\left(2 \mathrm{H}, \mathrm{t}, \mathrm{J}=7.34 \mathrm{~Hz},-\mathrm{CH}_{2}-\mathrm{C}_{11} \mathrm{H}_{23}\right), 7.33(1 \mathrm{H}, \mathrm{s},-\mathrm{N}-\mathrm{CH}-\mathrm{CH}-), 7.41(1 \mathrm{H}, \mathrm{s},-\mathrm{N}-\mathrm{CH}-$ $\mathrm{CH}), 9.90(1 \mathrm{H}, \mathrm{s},-\mathrm{N}-\mathrm{CH}-\mathrm{N}-) .{ }^{13} \mathrm{C} \mathrm{NMR}\left(200 \mathrm{~Hz}, \mathrm{CDCl}_{3}\right): \delta(\mathrm{ppm})=160.93(\mathrm{q}, \mathrm{J}=34.16 \mathrm{~Hz})$, $137.79,125.64,123.55,116.86$ (q, J = 294.37 Hz), 49.96, 36.11, 31.80, 30.10, 29.48 (2C), 29.38, 29.23 (2C), 28.83, 26.07, 22.58, 14.01 .

\section{Synthesis of $\left[\mathrm{C}_{12} \mathrm{mim}\right] \mathrm{Sal}$ and $\left[\mathrm{C}_{12} \mathrm{mim}\right] \mathrm{OAc}$}

Both ionic liquids were prepared adapting a to the procedure from Ferguson et. al. ${ }^{16}$ which includes the neutralization of the corresponding hydroxide ionic liquid with the desired acid as counter ion.

General procedure: $\left[\mathrm{C}_{12} \mathrm{mim}\right] \mathrm{Cl}$ (1 equivalent) was slowly mixed with 1 equivalent of concentrated sulfuric acid in a round bottom flask. The round-bottomed flask was fitted with a stopcock, the other end of which was connected to an open tube packed with $\mathrm{NaOH}$ pellets. The flask was heated up to $90^{\circ} \mathrm{C}$ and stirred for $2 \mathrm{~h}$, after which the open end of the $\mathrm{NaOH}$ packed tube was connected to a small diaphragm pump. The mixture was left overnight under vacuum at $90{ }^{\circ} \mathrm{C}$. The obtained $\left[\mathrm{C}_{12} \mathrm{mim}\right]\left[\mathrm{HSO}_{4}\right]$ was dissolved in hot deionized water $\left(95-100{ }^{\circ} \mathrm{C}, 25 \mathrm{~mL}\right)$ and slowly added to a solution of barium hydroxide octahydrate dissolved in hot deionized water $\left(95-100{ }^{\circ} \mathrm{C}, 55 \mathrm{~mL}\right)$. The cloudy reaction mixture was stirred, and allowed to cool to room temperature, then refrigerated. The white solid precipitate was removed via vacuum filtration $(\mathrm{P} 4$ glass sintered funnel with a $0.5 \mathrm{~cm}$ celite layer), washed with water (ca. $20^{\circ} \mathrm{C}, 50 \mathrm{~mL}$ ), and discarded. The highly basic hydroxide solution generated from the procedure was then diluted to $250 \mathrm{~mL}$ in a volumetric flask. From this $3 \mathrm{~mL}$ were taken, diluted with ca. $50 \mathrm{~mL}$ of water and titrated with $\mathrm{HCl} 0.05 \mathrm{M}$ followed by $\mathrm{pH}$ meter. From the equivalence point the required amount of the desired acid was calculated and added to the volumetric flask. Water was removed via lyophilisation, and the obtained product was dried at high vacuum (0.01 mbar) overnight. The crude product was re-dissolved in anhydrous DCM (100 mL), filtered, and the solvent was removed via evaporation. Remaining traces of volatiles were removed under high vacuum $(0.01$ mbar) overnight. 
Following the general procedure $\left[\mathrm{C}_{12} \mathrm{mim}\right] \mathrm{OAc}$ was obtained as off-white solid in $83 \%$ yield. $\mathrm{C}_{18} \mathrm{H}_{34} \mathrm{~N}_{2} \mathrm{O}_{2}$ (310.48): calculated $\mathrm{C}$ 69.63, $\mathrm{H}$ 11.04, N 9.02 \%; calculated (including $0.5 \times \mathrm{H}_{2} \mathrm{O}$ ) C 67.67, H 11.04, N 8.77\%; found C 67.52, H 11.56, N 9.03. $v_{\max }\left(\mathrm{cm}^{-1}\right): 2922(\mathrm{C}-\mathrm{H})$, $1666\left(\mathrm{CO}_{2}{ }^{-}\right) 1578(\mathrm{C}=\mathrm{C}), 1176(\mathrm{C}-\mathrm{N}) .{ }^{1} \mathrm{NMR}\left(\mathrm{CDCl}_{3}\right): \delta(\mathrm{ppm})=0.81\left(3 \mathrm{H}, \mathrm{br},-\mathrm{C}_{11} \mathrm{H}_{22}-\mathrm{CH}_{3}\right)$, $1.18\left(18 \mathrm{H}, \mathrm{m},-\mathrm{C}_{2} \mathrm{H}_{4}-\mathrm{C}_{9} \mathrm{H}_{18}-\mathrm{CH}_{3}\right), 1.80\left(2 \mathrm{H}, \mathrm{br},-\mathrm{CH}_{2}-\mathrm{CH}_{2}-\mathrm{C}_{10} \mathrm{H}_{21}\right), 1.91\left(2 \mathrm{H}, \mathrm{s}, \mathrm{CH}_{3} \mathrm{COO}\right), 3.99$ $\left(3 \mathrm{H}, \mathrm{s}, \mathrm{N}-\mathrm{CH}_{3}\right), 4.21\left(2 \mathrm{H}, \mathrm{t}, \mathrm{J}=4.21 \mathrm{~Hz},-\mathrm{CH}_{2}-\mathrm{C}_{11} \mathrm{H}_{23}\right), 7.14(1 \mathrm{H}, \mathrm{s},-\mathrm{N}-\mathrm{CH}-\mathrm{CH}-), 7.23(1 \mathrm{H}, \mathrm{s},-$ $\mathrm{N}-\mathrm{CH}-\mathrm{CH}), 10.91(1 \mathrm{H}, \mathrm{s},-\mathrm{N}-\mathrm{CH}-\mathrm{N}-) .{ }^{13} \mathrm{C} \mathrm{NMR}\left(200 \mathrm{~Hz}, \mathrm{CDCl}_{3}\right): \delta(\mathrm{ppm})=177.54,139.36$, 123.12 , 121.32, 49.79, 36.20, 31.79, 30.22, 29.49 (3C), 29.41, 29.28, 29.22, 28.93, 26.17, 24.96, $22.57,14.02$,

Following the general procedure $\left[\mathrm{C}_{12} \mathrm{mim}\right] \mathrm{Sal}$ was obtained as a yellow pale very viscous liquid in $63 \%$ yield. $\mathrm{C}_{23} \mathrm{H}_{36} \mathrm{~N}_{2} \mathrm{O}_{3}$ (388.55): calculated $\mathrm{C} 71.10, \mathrm{H} 9.34, \mathrm{~N} 7.21 \%$; calculated (including $\left.0.1 \mathrm{x} \mathrm{H}_{2} \mathrm{O}\right) \mathrm{C} 70.77, \mathrm{H} 9.35, \mathrm{~N} 7.18 \%$; found C 70.70, H 10.28, N 7.23\%, Cl 150 ppm. $v_{\max }\left(\mathrm{cm}^{-}\right.$ 1): $3394(\mathrm{O}-\mathrm{H}), 2923(\mathrm{C}-\mathrm{H}), 1575\left(\mathrm{COO}^{-}\right), 1455(\mathrm{C}=\mathrm{C}), 1385(\mathrm{Ar}-\mathrm{C}-\mathrm{C}), 1169(\mathrm{C}-\mathrm{N}) .{ }^{1} \mathrm{NMR}(200$ $\left.\mathrm{MHz}, \mathrm{CDCl}_{3}\right): \delta(\mathrm{ppm})=0.81\left(3 \mathrm{H}, \mathrm{t}, \mathrm{J}=6.26 \mathrm{~Hz},-\mathrm{C}_{11} \mathrm{H}_{22}-\mathrm{CH}_{3}\right), 1.16\left(18 \mathrm{H}, \mathrm{m},-\mathrm{C}_{2} \mathrm{H}_{4^{-}} \mathrm{C}_{9} \mathrm{H}_{18^{-}}\right.$ $\left.\mathrm{CH}_{3}\right), 1.75\left(2 \mathrm{H}, \mathrm{br},-\mathrm{CH}_{2}-\mathrm{CH}_{2}-\mathrm{C}_{10} \mathrm{H}_{21}\right), 3.94\left(3 \mathrm{H}, \mathrm{s}, \mathrm{N}-\mathrm{CH}_{3}\right), 4.12\left(2 \mathrm{H}, \mathrm{t}, \mathrm{J}=7.38 \mathrm{~Hz},-\mathrm{CH}_{2}-\right.$ $\left.\mathrm{C}_{11} \mathrm{H}_{23}\right), 6.63-6.78(2 \mathrm{H}, \mathrm{m}, \mathrm{Ar}), 7.03-7.20(3 \mathrm{H}, \mathrm{m}, \mathrm{Ar}), 7.86(1 \mathrm{H}, \mathrm{d}, \mathrm{J}=6.30,-\mathrm{N}-\mathrm{CH}-\mathrm{CH}-), 10.52$ $(1 \mathrm{H}, \mathrm{s},-\mathrm{N}-\mathrm{CH}-\mathrm{N}) .{ }^{13} \delta(\mathrm{ppm})=174.08,162.15,138.17,132.24,130.46,123.14,121.52,119.83$, $117.33,116.23,49.99,36.30,31.89,30.15,29.58$ (2C), 29.47, 29.33 (2C), 28.93, 26.20, 22.67, 14.11

\section{Conductivity measurements}

The samples were previously equilibrated at $(25.0 \pm 0.1){ }^{\circ} \mathrm{C}$ in a HAAKE K15 thermostat, then conductivity measurement were performed using a Mettler Toledo Seven Excellence system, equipped with a InLAB ${ }^{\circ} 741$-ISM electrode (cell constant $\mathrm{k}=0.105 \mathrm{~cm}^{-1}$, determined with a standard $\mathrm{KCl}$ solution). The sample was stirred before measurement to ensure homogeneous mixing. The plot of electrical conductivity versus surfactant concentration, typically consists of a two distinct linear regions. Critical micelle concentration $(\mathrm{cmc})$ values were calculated as the intersection point of these two linear regimes in the conductivity/concentration graph and the degree of micelle ionization, $\beta(=z / n$, where $z$ is the effective charge of the micelles and $n$ is the 
number of surfactant monomer in the micellar aggregate) was estimated from the ratio of slopes [17].

\section{Surface tension measurements}

Surface tension was determined with the Du Noüy ring method on a Krüss manual tensiometer K6 at room temperature. Each measurement was repeated five times, considering the arithmetic mean of the results with a relative standard deviation less than $0.5 \%$.

\section{Viscosity determination}

The viscosity of solutions was determined by using a micro Ostwald viscometer (SI Analytics $\mathrm{GmbH}$, Mainz, Germany, type and capillary no. 516 10/I ) and an automatic flow time measuring system ViscoSystem ${ }^{\circledR}$ AVS 370. The procedure is described in detail in literature [18].

\section{Isothermal titration calorimetry (ITC)}

The heat changes upon micellization were measured using a VP-ITC microcalorimeter from MicroCal, LLC (Northampton, MA, USA). Periodical calibration of the instrument has been proposed electrically by administering a known quantity of power through a resistive heater element located on the cell [19]. The precision of instrument has been also validated through binding of the cytidine 2'-monophosphate to the ribonuclease A active site. The standard chemical reaction is described elsewhere [20]. Degassed water in the titration cell was titrated with the degassed surfactant solution in the corresponding solvent from a $0.300 \mathrm{~mL}$ syringe at temperatures between 278.15 and $318.15 \mathrm{~K}$. Successive aliquots of surfactant solution were added into the calorimeter cell $(\mathrm{V}=1.386 \mathrm{~mL})$ under constant stirring through a motor driven syringe. The experimental data was analysed using the Origin 7.0 software provided by MicroCal. A detailed description of the procedure is given in our previous work [21]. 


\section{Thermodynamic analysis}

The experimental ITC data were fitted with a model function, derived on the basis of the massaction model for micellization of cationic surfactant. To make the applied procedure clearer, the thermodynamic analysis here is divided into three sections, whereas a detailed explanation of is given in the Supplementary material together with the algorithm of the fitting.

a) Model description. According to the mass-action model [22,23,24,25] the micellization process of a cationic surfactant at constant temperature, $T$, and pressure, $p$, may be described as

$n \mathrm{~S}^{+}+(n-z) \mathrm{C}^{-} \rightleftarrows \mathrm{M}^{z}$

where $\mathrm{S}^{+}$represents the monomeric state of surfactant, $\mathrm{C}^{-}$the corresponding counter ions and $\mathrm{M}^{\mathrm{Z}}$ the micellar aggregate of $n$ surfactant monomers with an effective charge of $z$. The equilibrium between species can be expressed by the apparent equilibrium constant (apparent because we are using molalities instead of activities - approximation acceptable at low concentrations), $K_{\mathrm{M}}$,

$$
K_{\mathrm{M}}=\frac{m_{\mathrm{M}}}{m_{\mathrm{S}}^{n} m_{\mathrm{C}}^{n-z}}
$$

where $m_{\mathrm{S}}$ is the molality of surfactant ions in monomeric form, $m_{\mathrm{C}}$ the molality of counterions and $m_{\mathrm{M}}$ the molality of micelles.

Surfactant solution with concentration above critical micelle concentration, cmc, can be considered as a mixed electrolyte solution with the total surfactant molality, $m$, containing fraction of surfactant in micellar form, $\alpha_{\mathrm{M}}=n \cdot m_{\mathrm{M}} / m$.

It follows that $K_{\mathrm{M}}$ can be expressed as 


$$
K_{\mathrm{M}}=\frac{\alpha_{\mathrm{M}} m^{1-n}}{n\left(1-\alpha_{\mathrm{M}}\right)^{n}\left(m\left(1-\alpha_{\mathrm{M}}(1-\beta)\right)\right)^{n(1-\beta)}}
$$

where $n$ is the aggregation number and $\beta(=z / n)$ the degree of micelle ionization.

b) Connection of the model to the experiment. To connect the proposed model with measured quantity $\Delta H$, we have to express enthalpy of solution in the titration cell obtained after $i$-th injection, $H_{\mathrm{i}}$, as

$$
H_{\mathrm{i}}=n_{1} \bar{H}_{1}+n_{\mathrm{S}} \bar{H}_{\mathrm{S}}+n_{\mathrm{C}} \bar{H}_{\mathrm{C}}+n_{\mathrm{M}} \bar{H}_{\mathrm{M}}
$$

where $n_{1}$ is the number of moles of solvent, $n_{\mathrm{S}}$ the number of moles of surfactant ions in monomeric form, $n_{\mathrm{C}}$ the number of moles of free counter ions, and $n_{\mathrm{M}}$ the number of moles of surfactant ions in micellar form and $\bar{H}_{1}, \bar{H}_{\mathrm{S}}, \bar{H}_{\mathrm{C}}$, and $\bar{H}_{\mathrm{M}}$ the corresponding partial molar enthalpies. By taking into account the total number of moles of surfactant, $n_{2}=n_{\mathrm{S}}+n_{\mathrm{M}}$, and counter ions, $n_{\mathrm{C}}=n_{\mathrm{S}}+\beta n_{\mathrm{M}}$, Eq. (4) becomes

$H_{\mathrm{i}}=n_{1} \bar{H}_{1}+n_{2}\left(\bar{H}_{\mathrm{S}}+\bar{H}_{\mathrm{C}}\right)+n_{\mathrm{M}} \Delta_{\mathrm{M}} H$

where the enthalpy of micelle formation, $\Delta_{\mathrm{M}} H$, is defined as

$$
\Delta_{\mathrm{M}} H=\left(\bar{H}_{\mathrm{M}}-\bar{H}_{\mathrm{S}}-(1-\beta) \bar{H}_{\mathrm{C}}\right) .
$$

Partial derivative of enthalpy with respect to $n_{2}$ at constant $p, T$, and $n_{1}$ in combination with Gibbs-Duhem equation (detailed explanation is given in the Supplementary material), leads to the relation for measured relative molar enthalpy, $\Delta H$, including the enthalpy of micellization, $\Delta_{\mathrm{M}} H$, which is assumed to be concentration independent and thus equal to its value in the standard state $\left(\Delta_{\mathrm{M}} H=\Delta_{\mathrm{M}} H^{0}\right)$, 
$\Delta H=\left(\bar{H}_{\mathrm{S}}+\bar{H}_{\mathrm{C}}-\right.$ const $)+\Delta_{\mathrm{M}} H^{0}\left(\frac{\partial n_{\mathrm{M}}}{\partial n_{2}}\right)_{n_{1}, p, T}$.

Standard state is hypothetical state and is $1 \mathrm{M}$ solution, which behaves as the solution at infinite dilution. Equation (7) is ITC model function primarily used to fit our experimental data. The fitting parameters within the model function are calculated by using set of equations which are presented in continuation.

Using the Gibbs-Helmholtz relation and the Guggenheim approximation for surfactant mean activity coefficient [26], the $\left(\bar{H}_{\mathrm{S}}+\bar{H}_{\mathrm{C}}\right)$ contribution below cmc can be expressed as

$\bar{H}_{\mathrm{S}}+\bar{H}_{\mathrm{C}}=\bar{H}_{2}^{0}+2 \cdot R T^{2}\left(\frac{A_{(T)}^{\prime} \sqrt{m}}{1+\sqrt{m}}+B_{(T)}^{\prime} m\right)$

where $\bar{H}_{2}^{0}$ represents the partial molar enthalpy of surfactant in its standard state. The coefficients $A_{(T)}^{\prime}$ and $B_{(T)}^{\prime}$ are temperature derivatives of the constants $A_{(T)}$ and $B_{(T)}$, that reflect solvent properties and ion-ion interactions, respectively [26]. Since the values of coefficients $A_{(T)}^{\prime}$ and $B_{(T)}^{\prime}$ are almost constant at all temperatures and they do not affect the values of other thermodynamic parameters significantly, we have concluded that Guggenheim approximation is adequate to represent ionic interactions in SAIL system.

Due to the small changes in concentrations of $\mathrm{S}^{+}$and $\mathrm{C}^{-}$ions above $\mathrm{cmc}$, their concentration and thus also their mean activity coefficient are assumed to remain constant and equal to its value at the cmc. Consequently the contribution $\left(\bar{H}_{\mathrm{S}}+\bar{H}_{\mathrm{C}}\right)$ above cmc can be also regarded as constant.

c) Fitting procedure. By help of well-known relation $\Delta_{\mathrm{M}} G^{0}=-\frac{R T}{n} \ln K_{\mathrm{M}}$, the ITC model function (Eq. (7)) may be described in terms of adjustable (fitting) parameters $n, \Delta_{\mathrm{M}} H^{0}, \Delta_{\mathrm{M}} G^{0}$, 
the coefficients $A_{(T)}^{\prime}$ and $B_{(T)}^{\prime}$ (Eq. (8)) and $\Delta_{\mathrm{M}} c_{p}^{0}$ in the case of global fitting (see explanation further) The $\left(\partial n_{\mathrm{M}} / \partial n_{2}\right)_{n_{1}, p, T}$ derivative in the Eq. (7) represents the fraction of surfactant molecules in micellar state $\mathrm{M}$ and can be derived from the apparent equilibrium constant $K_{\mathrm{M}}$ considering the mass-balance relations (see Supplementary material).

To perform a global fitting of the data (fitting of curves at all temperatures simultaneously) we must also include Kirchhoff's law

$$
\Delta_{\mathrm{M}} H^{0}(T)=\Delta_{\mathrm{M}} H^{0}\left(T_{\mathrm{r}}\right)+\Delta_{\mathrm{M}} c_{p}^{0}\left(T-T_{\mathrm{r}}\right)
$$

and the integrated Gibbs-Helmholtz equation

$$
\Delta_{\mathrm{M}} G^{0}(T)=T\left(\Delta_{\mathrm{M}} G^{0}\left(T_{\mathrm{r}}\right) / T_{\mathrm{r}}+\Delta_{\mathrm{M}} H^{0}\left(T_{\mathrm{r}}\right)\left[1 / T-1 / T_{\mathrm{r}}\right]+\Delta_{\mathrm{M}} c_{p}^{0}\left[1-T_{\mathrm{r}} / T-\ln \left(T / T_{\mathrm{r}}\right)\right]\right)
$$

where $\Delta_{\mathrm{M}} H^{0}\left(T_{\mathrm{r}}\right)$ and $\Delta_{\mathrm{M}} G^{0}\left(T_{\mathrm{r}}\right)$ are the standard enthalpy and the standard Gibbs free energy of micellization at some reference temperature $T_{\mathrm{r}} . \Delta_{\mathrm{M}} c_{p}^{0}$ is heat capacity change for micellization and was considered as constant. All above-mentioned adjustable parameters were obtained by fitting of the Eq. (7) to the experimental data points using the Levenberg-Marquardt nonlinear regression algorithm [27] for minimizing $\chi^{2}$ function (Eq. $z$ in Supplementary material). At this point, it must be emphasized that the Eqs. (2-8) and consequently the standard Gibbs free energies and entropies are based on the molality scale. We also fitted our experimental data on mole fraction scale and obtained parameters which were within the calculated error, but for clarity reason only parameters on molality scale are shown.

In this work, a global fitting of the model equation to the corresponding experimental curves at all the examined temperatures was performed giving a greater confidence in the proposed model and consequently in all the adjustable parameters [28]. The main presumption concerning the global fitting was temperature independence of the aggregation number, which turned out to be 
acceptable since the individual and global fitting parameter didn't differentiate too much. This approach was already successfully used in our previous work [29].

\section{Results and Discussion}

The dependence of experimental heat of dilution, $\Delta H$, on surfactant concentration (enthalpogram) for titration of $\left[\mathrm{C}_{12} \mathrm{mim}\right] \mathrm{Cl}$ in water in the investigated temperature range is shown in

Fig. 1(a). Similar enthalpy patterns were also obtained for other investigated systems at the same temperatures (Fig. S1 in the Supplementary material). In Fig. 1(b) the comparison of enthalpograms for $\left[\mathrm{C}_{\mathrm{X}} \mathrm{mim}\right] \mathrm{Cl}$ systems is. As can be seen on Fig. 1(a), the heat effect at 298.15 $\mathrm{K}$ at $\left[\mathrm{C}_{\mathrm{X}} \mathrm{mim}\right] \mathrm{Cl}$ systems is relatively weak and therefore the effect at $288.15 \mathrm{~K}$ is compared in Fig. 1(b).
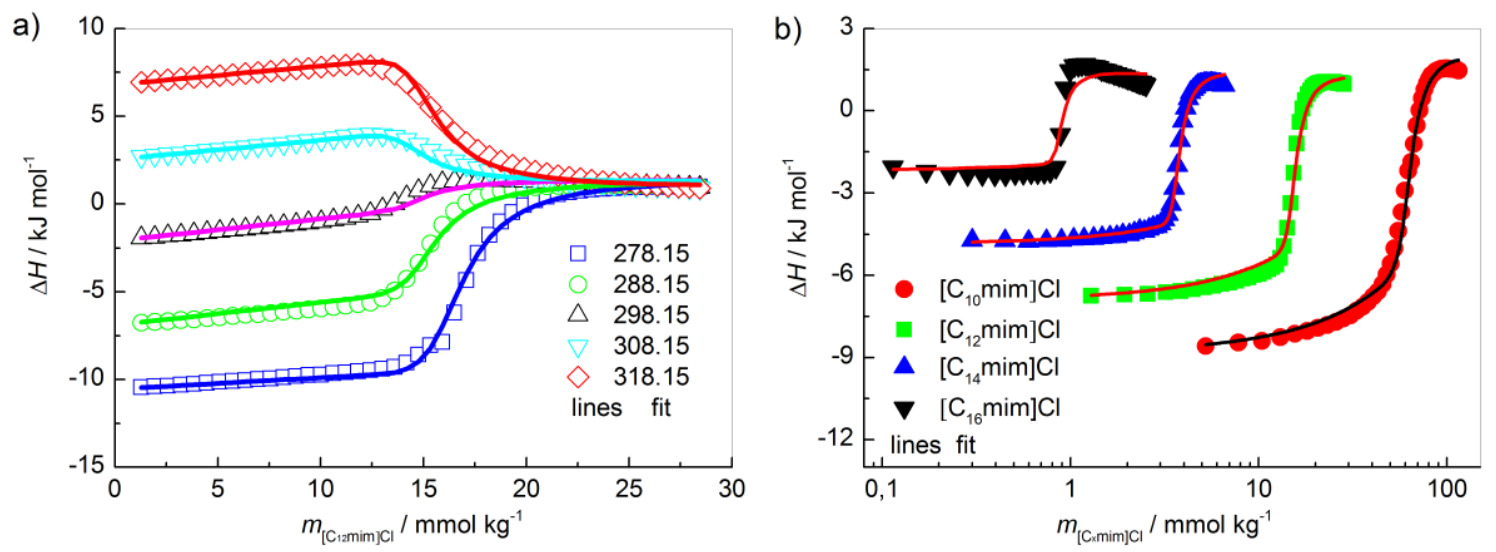

Fig. 1: a) Temperature dependent enthalpograms for $\left[\mathrm{C}_{12} \mathrm{mim}\right] \mathrm{Cl}$; b) enthalpograms for $\left[\mathrm{C}_{\mathrm{x}} \mathrm{mim}\right] \mathrm{Cl}$ at $288.15 \mathrm{~K}$ in water. Solid lines represent the fits according to the model function (Eq. (7)).

As it can be seen from Figs. 1 and S1 in Supplementary material, anomalies from purely sigmoidal behavior at some titration curves were observed, which cannot be fitted well (for example $\left[\mathrm{C}_{10} \mathrm{mim}\right] \mathrm{Cl}$ at higher temperatures, $\left[\mathrm{C}_{12} \mathrm{mim}\right] \mathrm{OMs}$ at $288.15 \mathrm{~K}$ and at $308.15 \mathrm{~K}$, $\left[\mathrm{C}_{12} \mathrm{mim}\right] \mathrm{OAc}$ at $288.15 \mathrm{~K}$ and at $\left.298.15 \mathrm{~K}\right]$ ). The experiment can be described as usually: the surfactant undergoes demicellization initially, which is followed by monomer dilution (at 
surfactant concentrations in the calorimetric cell below the $\mathrm{cmc}$ ). Thus, at the beginning of experiment the heat changes measured result from demicellization of surfactant micelles, dilution of monomers, corresponding counterions and their mutual interactions. After surfactant concentration in the calorimetric cell reaches the $\mathrm{cmc}$, solution undergoes micellar dilution only (and no further demicellization) with an appreciable change in enthalpy that remains nearly constant with increasing surfactant concentration.

Therefore, the whole enthalpy curve (Figs.1 and S1 in Supplementary material) consists of a three regions: two approximately horizontal or at least linear parts linked by a declining or increasing one. Evidently, investigated systems in general obey the same pattern as it has been observed for classical surfactants and was also represented in our previous work for alkyltrimethylammonium chlorides in water $[21,30]$. Obviously here the process at $\left[\mathrm{C}_{12} \mathrm{mim}\right] \mathrm{X}$ systems is strongly affected by the counter ions. The values of cmc and $\Delta_{\mathrm{M}} H^{0}$ were simultaneously determined by the fitting procedure and are listed together with other thermodynamic parameters in Table S1 in Supplementary material for all systems at all investigated temperatures. Here also the comparison with the (available) literature data and cmc values as obtained from different techniques are reported. In Fig. 2, values the degree of micelle ionization, as estimated from conductivity measurements and cmc values form ITC at 298.15 K are presented.
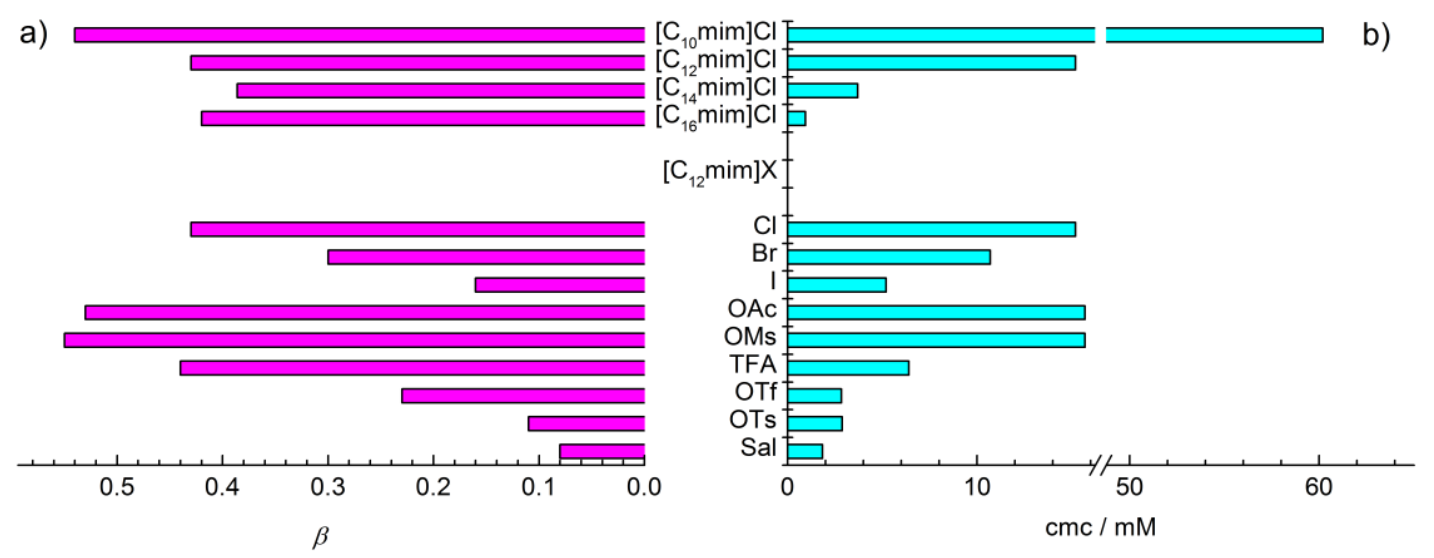

Fig. 2. a) Values for degree of micelle ionization, $\beta$, and b) critical micelle concentrations, cmc, for all investigated systems at $298.15 \mathrm{~K}$. 
From Figs. 1(b) and 2(b) (and in Table S1 in Supplementary material) it is evident that cmc is decreasing with the length of side alkyl chain in the imidazolium cation at $\left[\mathrm{C}_{\mathrm{x}} \mathrm{mim}\right] \mathrm{Cl}$, as it is usual for "classical" surfactants. The values of cmc, estimated in this work, are in reasonable agreement with the literature data. There is no explicit relation between degree of micelle ionization, $\beta$, and side alkyl chain length.

On the other hand, at $\left[\mathrm{C}_{12} \mathrm{mim}\right] \mathrm{X}$ systems $\mathrm{cmc}$ values decrease with increasing hydrophobicity of counterions. Thus $\mathrm{OAc}^{-}$is strongly hydrated (cosmotrop) and possesses thus the highest $\mathrm{cmc}$, $\mathrm{OTs}^{-}$, OTf ${ }^{-}$and $\mathrm{Sal}^{-}$are hydrophobic and their $\mathrm{cmc}$ values are lower. If hydrogen is replaced by fluoride the hydrophobic character of counterion is more pronounced what affects cmc crucially $\left(\mathrm{OAc}^{-}\right.$vs. $\mathrm{TFA}^{-}$; $\mathrm{OMs}^{-}$vs. OTf $)$. At $298.15 \mathrm{~K} \mathrm{cmc}^{-}$can be ranked in $\mathrm{OAc}^{-} \approx \mathrm{OMs}^{-} \approx \mathrm{Cl}^{-}>\mathrm{Br}^{-}$ $\mathrm{TFA}^{-}>\mathrm{I}^{-}>\mathrm{OTs}^{-} \approx \mathrm{OTf}^{-}>\mathrm{Sal}^{-}$.

The values of the degree of micelle ionization, $\beta$, at $\left[\mathrm{C}_{12} \mathrm{mim}\right] \mathrm{X}$ systems are strongly dependent on the counter ions and can be ranked in the order $\mathrm{Cl}^{-}>\mathrm{OAc}^{-} \approx \mathrm{OMs}^{-}>\mathrm{TFA}^{-}>\mathrm{Br}^{-}>\mathrm{OTf}^{-}>\mathrm{I}^{-}>$ $\mathrm{OTs}^{-}>\mathrm{Sal}^{-}$. Weakly hydrated counter ions ( $\left.\mathrm{I}^{-}, \mathrm{OTs}^{-}\right)$can be adsorbed more readily on the micellar surface, resulting in decreased charge repulsion between the ionic surfactant head groups. In contrast, the charge on the heavily hydrated $\mathrm{Cl}^{-}$is partially screened by the surrounding polar water molecules and these counter ions are thus less effective in reducing the charge repulsion. $\mathrm{Cl}^{-}$cannot approach the highly charged surface of the micelle as closely as less hydrated ions. Therefore, it can neither screen the charge at the surface of micelles nor reduce the surface potential as effectively as other, less hydrated ions. This results not only in higher values of $\beta$ but also in higher values of $\mathrm{cmc}$ (Fig. 2). [ $\left.\mathrm{C}_{12} \mathrm{mim}\right] \mathrm{OTs}$ and $\left[\mathrm{C}_{12} \mathrm{mim}\right]$ Sal express the outstanding low value of $\beta$ what can be ascribed to possible intercalation of anion possessing an aromatic ring in the micelle what has been already confirmed at dodecyltrimethylammmoinum chloride (DTACl) in the presence of $\mathrm{NaSal}[31]$.

In our previous work weak temperature dependence of $\beta$ at ionic surfactants was observed $[32,33]$. Thus, in this work $\beta$ values were determined at $298.15 \mathrm{~K}$ only and were regarded as temperature independent quantity since their values do not affect the thermodynamic analysis crucially. 
The temperature dependence of cmc shows typical U-shaped form (Fig. S2 in Supplementary material) reaching the minimum value $\mathrm{cmc}^{*}$ at the temperature $T^{*}$. These values, obtained from the corresponding derivative of the polynomial $\mathrm{cmc}=\mathrm{A}+\mathrm{B} T+\mathrm{C} T^{2}$, are listed in Table 1 , whereas the coefficients of polynomial are given in Table S2 in Supplementary material.

The comparison of thermodynamic functions at 298.15 K is given in Fig. 3. The reported errors in Table $\mathrm{S} 1$ in Supplementary material correspond to the precision of the experimental data and the fitting procedure assuming the proposed model is correct.

The micellization process of studied systems is endothermic at low temperatures and becomes exothermic at high temperatures, as it is evident from Table S1 in Supplementary material and Fig. S3 in Supplementary material. Such behaviour could be ascribed to the delicate balance between hydrophobic hydration of nonpolar parts (endothermic) and couter ion binding (exothermic) upon micellization, where former effect diminishes with temperature [34]. Interestingly, for $\left[\mathrm{C}_{12} \mathrm{mim}\right] \mathrm{I}$ and $\left[\mathrm{C}_{12} \mathrm{mim}\right] \mathrm{Sal}$ the micellization process would be endothermic at relatively low temperature, $\sim 270 \mathrm{~K}$. 


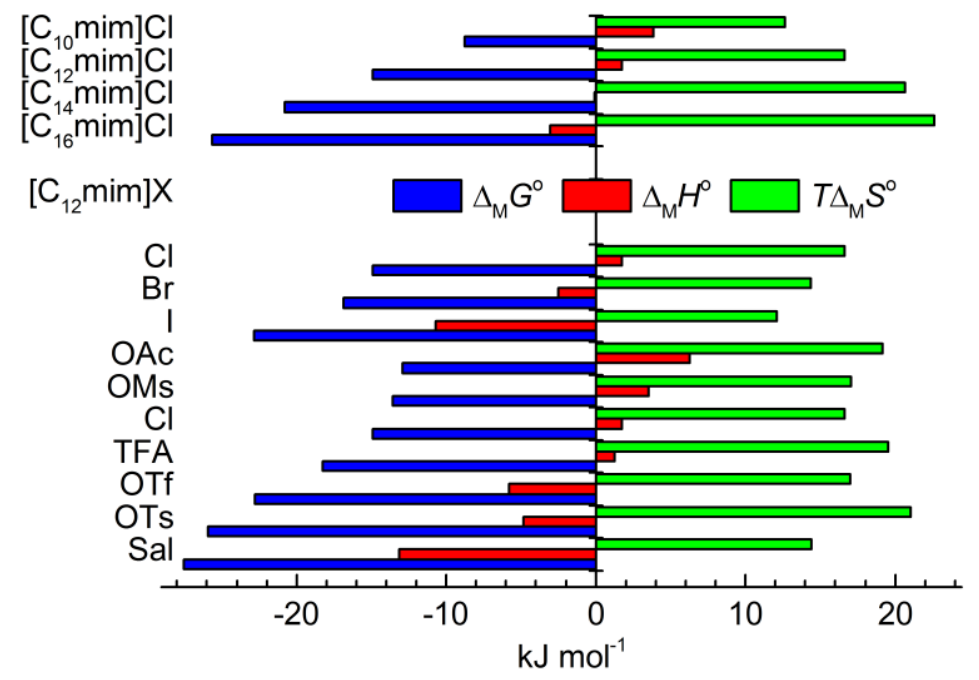

Fig. 3. Thermodynamic parameters of micellization for investigated systems in water at 298.15 $\mathrm{K}$ : standard enthalpy, $\Delta_{\mathrm{M}} H^{0}$, Gibbs free energy, $\Delta_{\mathrm{M}} G^{0}$, and entropy contributions, $T \Delta_{\mathrm{M}} S^{0}$, for micellization at investigated systems in water as obtained by the fitting procedure.

Similar change in the sign of $\Delta_{\mathrm{M}} H^{0}$ with increasing temperature has been already observed for number of ionic surfactants also [21,29,30,32,35]. As it is evident form Table 1, the temperature $T_{0}$ at which $\Delta_{\mathrm{M}} H^{0}=0$ is in excellent agreement with $T^{*}$ confirming that the micellization can be described well by applied mass-action model. According to the model, the Gibbs energy of micellization, $\Delta_{\mathrm{M}} G^{o}$, is a function of temperature, therefore the cmc minimum leads to a minimum in the $\Delta_{\mathrm{M}} G^{o} / T$. Following the Gibbs-Helmholtz relation, thus $\Delta_{\mathrm{M}} H^{o}$ must pass through zero. Here, temperature $T_{0}$ at which $\Delta H_{\mathrm{M}}^{0}=0$ is in the range of room temperature for all systems, except for $\left[\mathrm{C}_{12} \mathrm{mim}\right] \mathrm{I}$ and $\left[\mathrm{C}_{12} \mathrm{mim}\right] \mathrm{Sal}$, where $T_{0}=\sim 270 \mathrm{~K}$ could be estimated (Table S1, Fig. S3 in Supplementary material).

From Fig. 3 it is evident, that an interplay between enthalpy and entropy results in the negative values of Gibbs free energy, needed at spontaneous processes at constant $p$ and $T$. As it was already mention in Introduction, for diverse processes the linear relation between enthalpy and 
entropy was. For micellization process these linear relationship between the changes in entropy and enthalpy can be represented by

$$
\Delta_{\mathrm{M}} H^{0}=\Delta_{\mathrm{M}} H_{\mathrm{c}}+T_{\mathrm{c}} \Delta_{\mathrm{M}} S^{0}
$$

where $T_{\mathrm{c}}$ is called the compensation temperature and can be obtained from the slope of the straight line with $\Delta_{\mathrm{M}} H_{\mathrm{c}}$ as the intercept [36,37]. $T_{\mathrm{c}}$ can be interpreted as a characteristic of solute-solvent interactions, i.e., proposed as a measure of the "desolvation" part of the process of micellization and correlates to thus to the dehydration of the nonpolar parts of the self-assembled molecules [37]. $\Delta_{\mathrm{M}} H_{\mathrm{c}}$ characterizes the solute-solute interactions and is considered as an index of the "chemical" part of the process of micellization, connected to the formation of micelle of monomers [37].

Entropy-enthalpy plots for all investigated systems are presented in Fig. S4 in Supplementary material for all investigated SAILs, whereas the estimated values of $T_{\mathrm{c}}$ and $\Delta_{\mathrm{M}} H_{\mathrm{c}}$ are listed in Table 1.

Evidently, for all investigated systems values of $T_{\mathrm{c}}$ are close together, $T_{\mathrm{c}}=300 \pm 3 \mathrm{~K}$. According to Lumry and Rajender [36], for a variety of processes involving aqueous solutions of small molecules $T_{c}$ values lie in a narrow range between 250 and $350 \mathrm{~K}$. Even more, Lumry's law states that, for processes dominated by hydration, a value of $T_{\mathrm{c}} \cong 280 \mathrm{~K}$ should be assumed $[36,38,39]$. Thus, the value obtained here for studied SAILsk is indicative for processes dominated by dehydration [36].

It was assumed [37], that $\Delta_{\mathrm{M}} H_{\mathrm{c}}$ represents the strength of the solute-solute interactions at surfactant aggregation when the entropic contribution to micellization is zero i.e., $\Delta_{\mathrm{M}} S^{0}=0$. The increase in $\Delta_{\mathrm{M}} H_{\mathrm{c}}$ corresponds thus to a decrease in the stability of the structure of the micelles. From Table 2 is evident that $\Delta_{\mathrm{M}} H_{\mathrm{c}}$ is ranked in the order $\left[\mathrm{C}_{10} \mathrm{mim}\right] \mathrm{Cl}>\left[\mathrm{C}_{12} \mathrm{mim}\right] \mathrm{Cl}\left[\mathrm{C}_{14} \mathrm{mim}\right] \mathrm{Cl}$ $>\left[\mathrm{C}_{16} \mathrm{mim}\right] \mathrm{Cl}$. It can be assumed that the self-assembled structures with $\mathrm{C}_{16}$ are more densely packed then those with $\mathrm{C}_{10}$, as it is usual also at "classical" ionic surfactants $[37,40]$. 
In other words, the effect of this so-called "chemical part" of the process in micellization diminishes as the alkyl chain length decreases. In our previous work [37] it was found, that the value of $\Delta_{\mathrm{M}} H_{\mathrm{c}}$ decreases by $\sim 3.9 \mathrm{~kJ} \cdot \mathrm{mol}^{-1}$ when the alkyl chain length increases by one methylene unit for an ionic surfactant, and less $\left(\sim 2.9 \mathrm{~kJ} \cdot \mathrm{mol}^{-1}\right)$ for a nonionic surfactant $\mathrm{C}_{i} \mathrm{E}_{8}$.

As it is evident from Table 1, for investigated SAILs value of $\Delta_{\mathrm{M}} H_{\mathrm{c}}$ decreases for $3.1 \mathrm{~kJ} \cdot \mathrm{mol}^{-1}$ at increasing the side alkyl chain for one methylene group from $\left[\mathrm{C}_{10} \mathrm{mim}\right] \mathrm{Cl}$ to $\left[\mathrm{C}_{12} \mathrm{mim}\right] \mathrm{Cl}$, for $2.9 \mathrm{~kJ} \cdot \mathrm{mol}^{-1}$ from $\left[\mathrm{C}_{12} \mathrm{mim}\right] \mathrm{Cl}$ to $\left[\mathrm{C}_{14} \mathrm{mim}\right] \mathrm{Cl}$, and for $2.6 \mathrm{~kJ} \cdot \mathrm{mol}^{-1}$ from $\left[\mathrm{C}_{14} \mathrm{mim}\right] \mathrm{Cl}$ to $\left[\mathrm{C}_{16} \mathrm{mim}\right] \mathrm{Cl}$, what is in reasonable agreement with reported findings [37].

For surfactants possessing $\mathrm{C}_{12}$-alkyl chain, value of $\Delta_{\mathrm{M}} H_{\mathrm{c}}=\sim-35 \mathrm{~kJ} \mathrm{~mol}^{-1}$ is reported [37], but it was determined on very narrow choice of counterions $\left(\mathrm{Br}^{-}, \mathrm{Na}^{+}\right)$. In this work for $\Delta_{\mathrm{M}} H_{\mathrm{c}}$ values from $-13.0 \mathrm{~kJ} \mathrm{~mol}^{-1}$ ([ $\left.\left.\mathrm{C}_{12} \mathrm{mim}\right] \mathrm{OAc}\right)$ to $-27.7 \mathrm{~kJ} \mathrm{~mol}^{-1}$ ([ $\left.\left.\mathrm{C}_{12} \mathrm{mim}\right] \mathrm{Sal}\right)$ were estimated. Thus $\Delta_{\mathrm{M}} H_{\mathrm{c}}$ depends strongly on the counterion, as it is evident also from Table 1.

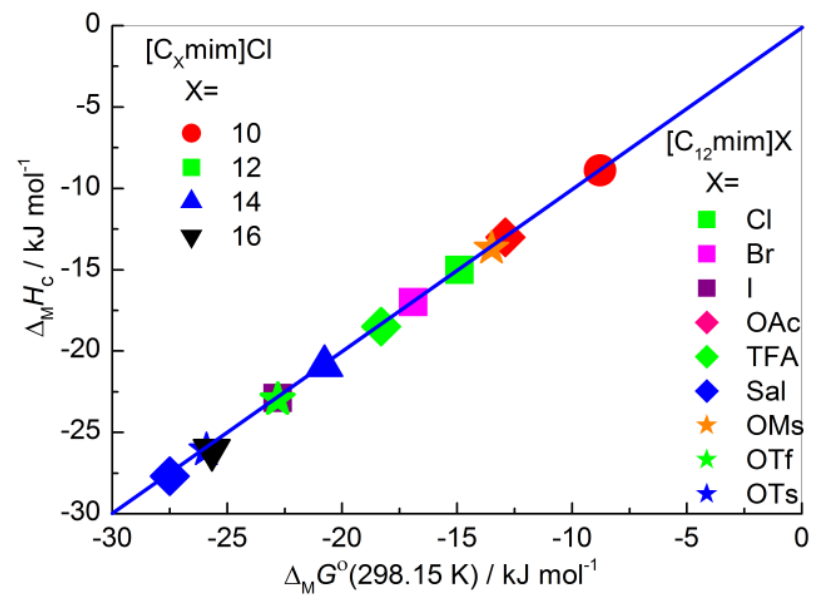

Fig. 4. Intercepts of the EEC plot, $\Delta_{\mathrm{M}} H_{\mathrm{c}}$, as a function of $\Delta_{\mathrm{M}} G^{o}(298.15 \mathrm{~K})$ for all investigated systems. 
Unfortunately, there is no data on the effect of the counterions on the enthalpy-entropy compensation effect in the literature. But having the look on the Fig. 4, presenting the $\Delta_{\mathrm{M}} H_{\mathrm{c}}$ as a function of $\Delta_{\mathrm{M}} G^{o}(298.15 \mathrm{~K})$, we can see that all values are excellent fitted to the same line starting in the origin with the slope of 1 . There is no doubt that the length of alkyl chain and the counter ions influence the micellization process. As it is evident form Figs. 2 and 3 and results in Table S1 in Supplementary material, cmc, $\beta$, and all thermodynamic functions are strongly dependent on properties of system. But there is no evidence that there is some extrathermodynamic mechanism for $\Delta \mathrm{H}-\Delta \mathrm{S}$ compensation. Values of $\Delta_{\mathrm{M}} H_{\mathrm{c}}$, determined in these work for SAILs with four different alkyl chain and for nine different counter ions for the SAILs with $\mathrm{C}_{12}$-alkyl chain are practically identical to the value of $\Delta_{\mathrm{M}} G^{o}$ near $T_{\mathrm{c}}$. Thus it can be concluded that in this case EEC is the fact, arising from the relationship $\Delta \mathrm{G}=\Delta \mathrm{H}-\mathrm{T} \Delta \mathrm{S}$. An inspections of values for $\Delta_{\mathrm{M}} G^{o}$ in Table $\mathrm{S} 1$ in Supplementary material reveals, that for a separate system micellization process occurs at the nearly constant $\Delta_{\mathrm{M}} G^{o}\left( \pm \sim 2 \mathrm{~kJ} \cdot \mathrm{mol}^{-1}\right)$, but there are bigger differences among them, for example $\sim 15 \mathrm{~kJ} \cdot \mathrm{mol}^{-1}$ between $\left[\mathrm{C}_{10} \mathrm{mim}\right] \mathrm{Cl}$ and $\left[\mathrm{C}_{16} \mathrm{mim}\right] \mathrm{Cl}$ and also between $\left[\mathrm{C}_{12} \mathrm{mim}\right] \mathrm{OAc}$ and $\left[\mathrm{C}_{12} \mathrm{mim}\right] \mathrm{Sal}$.

Nevertheless, the main driving force for the formation of micelles is the apparent disaffinity of water and the nonpolar (interacting) surfaces known as hydrophobic effect. The parameter that illustrates this effect is the heat capacity of micellization, $\Delta_{\mathrm{M}} c_{p}^{0}$, which is highly negative (Table 1), what can be ascribed to the removal of water molecules from contact with nonpolar surface area upon micelle formation [41]. However, their values are considerably dependent on the counter ions.

By modeling the micellization processes as a transfer of surfactant molecules into the micellar phase, the heat capacity can be expressed in terms of the change of water accessible nonpolar and polar surface areas, derived by Spolar et al. [42] from protein folding

$$
\Delta_{M} c_{p}^{o}\left(\mathrm{~J} \cdot \mathrm{K}^{-1} \cdot \mathrm{mol}^{-1}\right)=-1.34( \pm 0.33) \cdot \Delta \mathrm{A}_{\mathrm{np}}\left(\stackrel{o}{\mathrm{~A}^{2}}\right)+0.59( \pm 0.17) \cdot \Delta \mathrm{A}_{\mathrm{p}}\left(\stackrel{\circ}{\mathrm{A}^{2}}\right)
$$


where $\Delta \mathrm{A}_{\mathrm{p}}$ stand for the loss of water accessible polar and $\Delta \mathrm{A}_{\mathrm{p}}$ for nonpolar surface area upon protein folding. Because the hydrophilic head groups of non-ionic surfactants remain hydrated upon micelle formation, the "theoretical" contribution of water accessible nonpolar surface area change to the heat capacity change upon micelle formation, $\Delta_{\mathrm{M}} c_{p}^{0}\left(\mathrm{th}_{\mathrm{np}}\right)$, can be assumed to reflect only the change in exposure of the hydrophobic tails to water. Consequently, the Eq. (12) is reduced to

$$
\Delta_{M} c_{p}^{o}\left(\mathrm{th}_{\mathrm{np}}\right)\left(\mathrm{J} \cdot \mathrm{K}^{-1} \cdot \mathrm{mol}^{-1}\right)=-1.34( \pm 0.33) \cdot \Delta \mathrm{A}_{\mathrm{np}}\left(\stackrel{\circ}{\mathrm{O}^{2}}\right)
$$

This approach turned out as useful for a series of non-ionic surfactants [43,44].

According to Richards [45], water accessible surface area of a methylene group is $30 \AA^{2}$ and 88 $\AA^{2}$ for a methyl group. Thus $\Delta \mathrm{A}_{\mathrm{np}}$ of the hydrophobic tails of the surfactants investigated in this study is $358,418,478$ and $538 \AA^{2}$ for the $\mathrm{C}_{10}, \mathrm{C}_{12}, \mathrm{C}_{14}$ and $\mathrm{C}_{16}$ alkyl chain, respectively, giving the values of $\Delta_{\mathrm{M}} c_{\mathrm{p}}^{0}\left(\mathrm{th}_{\mathrm{np}}\right)=-479,-560,-640$ and $-720 \mathrm{~J} \cdot \mathrm{K}^{-1} \cdot \mathrm{mol}^{-1}$ for $\mathrm{C}_{10}, \mathrm{C}_{12}, \mathrm{C}_{14}$ and $\mathrm{C}_{16}$ alkyl chain, respectively. Comparison of $\Delta_{\mathrm{M}} c_{\mathrm{p}}^{0}\left(\mathrm{th}_{\mathrm{np}}\right)$, estimated by Eq. (13) with $\Delta_{\mathrm{M}} c_{\mathrm{p}}^{0}(\exp )$, as illustrated in Fig. 5, reveals that there is an evident discrepancy between $\Delta_{\mathrm{M}} c_{\mathrm{p}}^{0}\left(\mathrm{th}_{\mathrm{np}}\right)$ and $\Delta_{\mathrm{M}} c_{\mathrm{p}}^{0}(\exp )$. This discrepancy can be explained in two ways: 

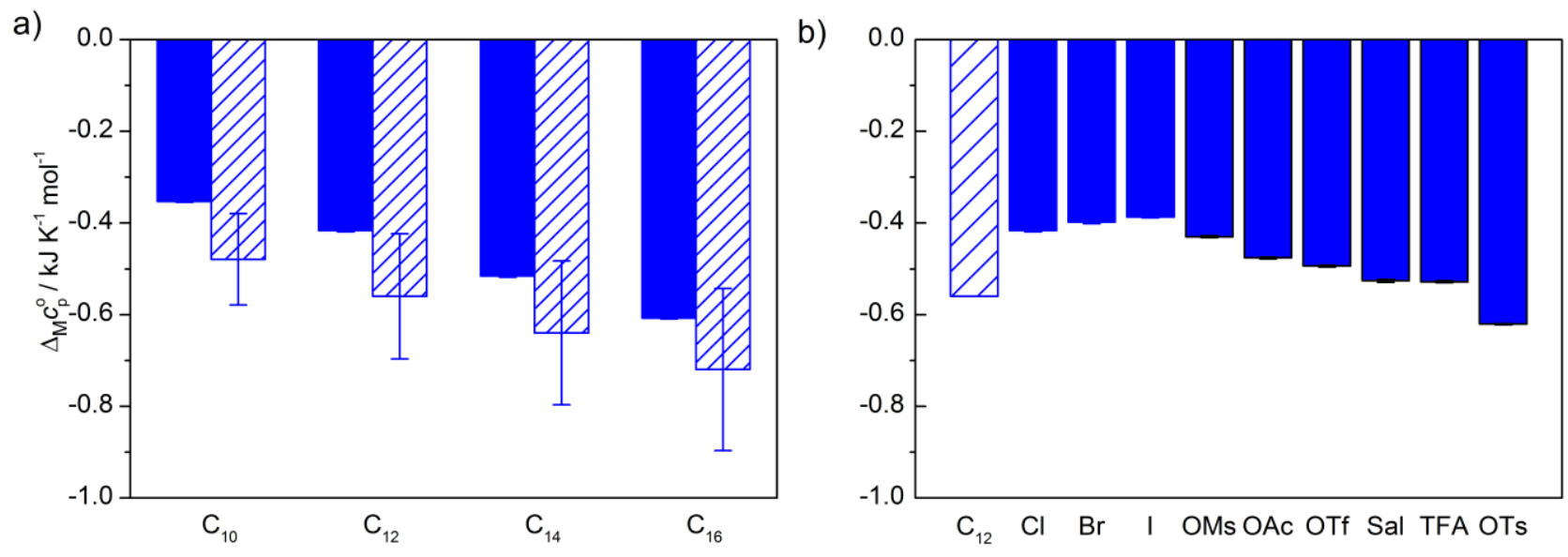

Fig. 5. Comparison of theoretical and experimental values of heat capacity changes upon micllization process, $\Delta_{\mathrm{M}} c_{\mathrm{p}}^{0}$, for a) $\left[\mathrm{C}_{\mathrm{X}} \mathrm{mim}\right] \mathrm{Cl}$ and b) $\left[\mathrm{C}_{12} \mathrm{mim}\right] \mathrm{X}$.

a) It can be assumed that there are still water molecules in the interior of the micelle upon micellization and thus the $\Delta \mathrm{A}_{\mathrm{np}}$ estimated by approach of Richards [45] mentioned above overestimates. That is, the "real" $\Delta \mathrm{A}_{\mathrm{np}}$ is smaller than that of Richards. Actually, the low aggregation numbers, $\mathrm{n}_{\text {agg }}$, of studied surfactants obtained by the fitting procedure (see Table 1) support the above presumption of loose aggregates with lots of water molecules still in contact with hydrocarbon skeleton even after micelles are formed for $\left[\mathrm{C}_{\mathrm{x}} \mathrm{mim}\right] \mathrm{Cl}$.

b) The Eq. (13) holds well for non-ionic surfactants [43,44], but it is not valid for ionic surfactants. Positive contribution of removal of water accessible polar surface area to the heat capacity change of micellization should also be considered and cannot be neglected, consistent with the findings for the heat capacity change upon protein folding [42]. It is believed that ionic surfactant are fully dissociated in aqueous solution when the surfactant concentration is below its $\mathrm{cmc}$. But this is not the case upon micellization, where the partially binding of counterions to the micelles results in the values of degree of micelle ionization lower then $1(0.1<\beta<0.6$, Fig. 2(b). Thus, the contribution of the removal of water accessible polar surface area, $\Delta \mathrm{A}_{\mathrm{p}}$, should not be neglected in the case of ionic surfactants. However no direct correlation between $\Delta_{\mathrm{M}} c_{\mathrm{p}}^{0}$ and $\beta$ can be deduced (Figs. 2, 5 and S5 in Supplementary material). Interestingly, the difference 
between $\Delta_{\mathrm{M}} c_{\mathrm{p}}^{0}(\exp )$ and $\Delta_{\mathrm{M}} c_{\mathrm{p}}^{0}\left(\mathrm{th}_{\mathrm{np}}\right)$ for the $\left[\mathrm{C}_{\mathrm{x}} \mathrm{mim}\right] \mathrm{Cl}$ systems, as illustrated in Fig. 5(a), is almost constant $127 \pm 12 \mathrm{~J} \mathrm{~mol}^{-1} \mathrm{~K}^{-1}$, that implies the removal of water accessible polar surface area due to the partial binding of counterions $\left(\mathrm{Cl}^{-}\right)$to the micelles is almost independent of alkyl chain length of ionic liquid $\left[\mathrm{C}_{\mathrm{x}} \mathrm{mim}\right] \mathrm{Cl}$. In addition, the influence of counterion on $\Delta_{\mathrm{M}} c_{\mathrm{p}}^{0}$ for $\left[\mathrm{C}_{12} \mathrm{mim}\right] \mathrm{X}$ systems is illustrated in Fig. $5(\mathrm{~b})$. If simply consider three systems: $\left[\mathrm{C}_{12} \mathrm{mim}\right] \mathrm{Cl}$, $\left[\mathrm{C}_{12} \mathrm{mim}\right] \mathrm{Br}$ and $\left[\mathrm{C}_{12} \mathrm{mim}\right] \mathrm{I}$, it is obvious to observe that the difference between $\Delta_{\mathrm{M}} c_{\mathrm{p}}^{0}(\exp )$ and $\Delta_{\mathrm{M}} c_{\mathrm{p}}^{0}\left(\mathrm{th}_{\mathrm{np}}\right)$ for the systems increases along with an increase in size of anion. It is plausible to conjecture that the removal of water accessible polar surface area also increases along with an increase in size of counterion binding onto the micelle but it can be concluded that $\Delta \mathrm{A}_{\mathrm{p}}$ part here cannot be neglected.

Recently, the incorporation of hydrophobic part of counter ion (benzene ring) in the micelle was confirmed for hydroxybenzoates [31, 46] and parabens [18] at micellization of dodecyltrimethylammonium chloride $(\mathrm{DTACl})$ in water. In this case the contribution for the removal of the hydrophobic part of counterion from the contact with water after micellization to the $\Delta_{\mathrm{M}} c_{p}^{0}$ can be assumed. Thus, the "hydrophobic" anions (OTs-, OTf-, TFA' and $\left.\mathrm{Sal}^{-}\right)$can be partially incorporated in the micelle and therefore the hydrophobic part of anion can contribute to the $\Delta \mathrm{A}_{\mathrm{np}}$. The result of such incorporation frequently leads to the formation of elongated or rodlike micelles at higher concentrations, which also indicate our viscosity measurements (Fig. S6 in Supplementary material). This was, for example, already confirmed for $\left[\mathrm{C}_{16} \mathrm{mim}\right] \mathrm{OTs}$ by Singh et al. using various methods [47]. 
Table 1. Aggregation number for of micelles, $n_{\mathrm{agg}}$, the temperature, $T^{*}(\mathrm{cmc})$, at the minimum critical micelle concentration, cmc*, temperature $T_{0}$ at $\Delta_{\mathrm{M}} H^{0}=0$, together with the "chemical part" of the micellization process, $\Delta_{\mathrm{M}} H_{c}$, compensation temperature, $T_{c}$, and standard heat capacity change upon micelle formation, $\Delta_{\mathrm{M}} c_{\mathrm{p}}^{0}$, for the investigated systems. ${ }^{\mathrm{a}}$

\begin{tabular}{|l|c|c|c|c|c|c|c|}
\hline & $n_{\mathrm{agg}}$ & $T^{*}(\mathrm{cmc})$ & $\mathrm{cmc}^{*}$ & $T_{0}$ & $\Delta_{\mathrm{M}} H_{\mathrm{c}}$ & $T_{\mathrm{c}}$ & $\Delta_{\mathrm{M}} c_{\mathrm{p}}^{0}$ \\
\hline$\left[\mathrm{C}_{10} \mathrm{mim}\right] \mathrm{Cl}$ & $13.4 \pm 0.1$ & 309.0 & $58.2 \pm 0.1$ & 309.0 & $-8.9 \pm 0.1$ & $298 \pm 3$ & $-353 \pm 2$ \\
\hline$\left[\mathrm{C}_{12} \mathrm{mim}\right] \mathrm{Cl}$ & $16.33 \pm 0.06$ & 302.9 & $15.2 \pm 0.8$ & 302.3 & $-15.0 \pm 0.2$ & $297 \pm 3$ & $-417 \pm 2$ \\
\hline$\left[\mathrm{C}_{12} \mathrm{mim}\right] \mathrm{Br}$ & $16.82 \pm 0.01$ & 291.9 & $10.5 \pm 0.5$ & 291.8 & $-17.0 \pm 0.2$ & $297 \pm 4$ & $-398 \pm 3$ \\
\hline$\left[\mathrm{C}_{12} \mathrm{mim}\right] \mathrm{I}$ & $17.6 \pm 0.2$ & 271.0 & $4.6 \pm 0.3$ & 270.4 & $-22.9 \pm 0.2$ & $297 \pm 4$ & $-387 \pm 2$ \\
\hline$\left[\mathrm{C}_{12} \mathrm{mim}\right] \mathrm{OAc}$ & $10.4 \pm 0.3$ & 311.3 & $16.7 \pm 0.9$ & 311.2 & $-13.0 \pm 0.2$ & $297 \pm 4$ & $-476 \pm 2$ \\
\hline$\left[\mathrm{C}_{12} \mathrm{mim}\right] \mathrm{OMs}$ & $21.8 \pm 0.1$ & 306.3 & $15.2 \pm 0.8$ & 306.3 & $-13.7 \pm 0.2$ & $298 \pm 3$ & $-430 \pm 2$ \\
\hline$\left[\mathrm{C}_{12} \mathrm{mim}\right] \mathrm{OTs}$ & $8.20 \pm 0.02$ & 290.2 & $2.8 \pm 0.1$ & 290.5 & $-26.1 \pm 0.2$ & $298 \pm 3$ & $-621 \pm 1$ \\
\hline$\left[\mathrm{C}_{12} \mathrm{mim}\right] \mathrm{OTf}$ & $16.9 \pm 0.1$ & 286.3 & $2.7 \pm 0.1$ & 286.5 & $-23.0 \pm 0.2$ & $299 \pm 4$ & $-494 \pm 2$ \\
\hline$\left[\mathrm{C}_{12} \mathrm{mim}\right] \mathrm{TFA}$ & $17.2 \pm 0.2$ & 301.3 & $6.4 \pm 0.3$ & 300.6 & $-18.5 \pm 0.3$ & $298 \pm 4$ & $-528 \pm 1$ \\
\hline$\left[\mathrm{C}_{12} \mathrm{mim}\right] \mathrm{Sal}$ & $9.3 \pm 0.8$ & 275.5 & $1.66 \pm 0.09$ & 273.2 & $-27.7 \pm 0.2$ & $298 \pm 3$ & $-526 \pm 2$ \\
\hline$\left[\mathrm{C}_{14} \mathrm{mim}\right] \mathrm{Cl}$ & $20.6 \pm 0.1$ & 297.6 & $3.7 \pm 0.2$ & 298.0 & $-20.9 \pm 0.2$ & $298 \pm 3$ & $-516 \pm 2$ \\
\hline$\left[\mathrm{C}_{16} \mathrm{mim}\right] \mathrm{Cl}$ & $11.1 \pm 0.1$ & 292.7 & $0.92 \pm 0.05$ & 293.1 & $-26.1 \pm 0.2$ & $302 \pm 3$ & $-608 \pm 2$ \\
\hline
\end{tabular}

${ }^{\mathrm{a}}$ Units: $T^{*}(\mathrm{cmc}), \mathrm{K} ; \mathrm{cmc}^{*}, \mathrm{mmol} \mathrm{kg}{ }^{-1} ; T_{0}, \mathrm{~K} ; \Delta_{\mathrm{M}} H_{\mathrm{c}}, \mathrm{kJ} \cdot \mathrm{mol}^{-1} ; T_{\mathrm{c}}, \mathrm{K} ; \Delta_{\mathrm{M}} c_{\mathrm{p}}^{0}, \mathrm{~J} \cdot \mathrm{K}^{-1} \cdot \mathrm{mol}^{-1}$. 


\section{Conclusions}

The present work clearly shows the great potential of surface active ionic liquids (SAILs) at investigation of thermodynamic of micellization process in solutions due to possible variations in the structure of chain length and counter ions. In many ways their behavior is identical to those observed by "usual" cationic surfactants: the critical micelle concentration is decreasing with the length of hydrophobic chain and expresses a minimum in the temperature dependence. In general, the micellization process is endothermic at low temperatures and exothermic at high temperatures, but in this work it was verified that the influence of counter ions plays an extremely important role. It was confirmed, that the hydrophobicity of counter ions evidently contribute to the heat capacity change and the water accessible surface area removal upon burial of non-polar group from the contact with water at micellization process. Even more, it can be assumed that all hydrophobic anions (OTs ${ }^{-}, \mathrm{OTf}^{-}, \mathrm{TFA}^{-}$and $\left.\mathrm{Sal}^{-}\right)$are partially incorporated in the micelle.

Enthalpy-entropy compensation (EEC) plots exhibit nearly parallel slopes for all studied SAILs giving compensation temperatures $T_{\mathrm{c}}=300 \pm 3 \mathrm{~K}$, indicating the domination of dehydration by micellization process at all studied SAILs. The interceptions of these plots, $\Delta_{\mathrm{M}} H_{\mathrm{c}}$ as the measure for so-called "chemical part" of the micellization, turned out as being strongly correlated to the $\Delta_{\mathrm{M}} G^{0}$, leading to the conclusion that at micellization process entropy-enthalpy compensation is the fact, arising from the relationship $\Delta \mathrm{G}=\Delta \mathrm{H}-\mathrm{T} \Delta \mathrm{S}$.

Finally, $\Delta_{\mathrm{M}} c_{p}^{0}$ was correlated with the removal of solvent accessible surface areas of SAILs and counterion from the contact with water after micellization. From the discrepancies between experimental and theoretical values of $\Delta_{\mathrm{M}} c_{p}^{0}$ it can be assumed, that there are still are still water molecules in the interior of the micelle upon micellization or/and that also the contribution of the removal of polar water accessible surface should be taken into account in the case of ionic surfactants. 


\section{Note}

The authors declare no competing financial interests.

\section{Acknowledgements}

The financial support by the Slovenian Research Agency through Grant No. P1-0201 and the Austrian Science Fund (FWF Project P25504-N28) is gratefully acknowledged. The work was partially supported by COST Action CM1206. 


\section{References}

[1] M. Blesic, M. H. Marques, N. V. Plechkova, K. R. Seddon, L. P. N. Rebelo, A. Lopes, Selfaggregation of ionic liquids: Micelle formation in aqueous solution, Green Chem. 9 (2007) 481490.

[2] A. Cornellas, L. Perez, F. Comelles, I. Ribosa, A. Manresa, M. T. Garcia, Self-aggregation and antimicrobial activity of imidazolium and pyridinium based ionic liquids in aqueous solution, J. Colloid Interface Sci. 355 (2011) 164-171.

[3] O. A. El Seoud, P. A. R. Pires, T. Abdel-Moghny, E. L. Bastos, Synthesis and micellar properties of surface-active ionic liquids: 1-Alkyl-3-methylimidazolium chlorides, J. Colloid Interface Sci. 313 (2007) 296-304.

[4] M. Blesic, A. Lopes, E. Melo, Z. Petrovski, N. V. Plechkova, J. N. Canongia Lopes, K. R. Seddon, L. P. N. Rebelo, On the self-aggregation and fluorescence quenching aptitude of surfactant ionic liquids, J. Phys. Chem. B 112 ( 2008) 8645-8650.

[5] M. T. Garcia, I. Ribosa, L. Perez, A. Manresa, F. Comelles, Self-assembly and antimicrobial activity of long-chain amide-functionalized ionic liquids in aqueous solution, Colloids Surface B 123 (2014) 318-325.

[6] J. Nowicki, J. Łuczak, D. Stańczyk, Dual functionality of amphiphilic 1-alkyl-3methylimidazolium hydrogen sulfate ionic liquids: surfactants with catalytic function, RSC Adv. 6 (2016) 11591-11601.

[7] M. Blesic, M. Swadźba-Kwaśny, J. D. Holbrey, J. N. Canongia Lopes, K. R. Seddon, L. P. N. Rebelo, New catanionic surfactants based on 1-alkyl-3-methylimidazolium alkylsulfonates, $[\mathrm{C}(\mathrm{n}) \mathrm{H}(2 \mathrm{n}+1) \mathrm{mim}][\mathrm{C}(\mathrm{m}) \mathrm{H}(2 \mathrm{~m}+1) \mathrm{SO}(3)]$ : Mesomorphism and aggregation, Phys. Chem. Chem. Phys. 11 (2009) 4260-4268. 
[8] A. B. Pereiro, J. M. M. Araújo, F. S.Teixeira, I. M. Marrucho, M. M. Piñeiro, L. P. N. Rebelo, Aggregation behavior and total miscibility of fluorinated ionic liquids in water, Langmuir 31 (2015) 1283-1295.

[9] M. Anouti, J. Jones, A. Boisset, J. Jacquemin, M. Caillon-Caravanier, D. Lemordant, Aggregation behavior in water of new imidazolium and pyrrolidinium alkycarboxylates protic ionic liquids, J. Colloid Interface Sci. 340 (2009) 104-111.

[10] A. K. Ressmann, R. Zirbs, M. Pressler, P. Gaertner, K. Bica, Surface-active ionic liquids for micellar extraction of piperine from black pepper, Z. Naturforsch. B 68b (2013) 1129-1137. [11] K. Bica, P. Gärtner, P. J. Gritsch, A. K. Ressmann, C. Schröder, R. Zirbs, Micellar catalysis in aqueous-ionic liquid systems, Chem. Commun. 48 (2012) 5013-5015.

[12] A. Cognigni, P. Gärtner, R. Zirbs, H. Peterlik, K. Prochazka, C. Schröder, K. Bica, Surfaceactive ionic liquids in micellar catalysis: Impact of anion selection on reaction rates in nucleophilic substitutions, Phys. Chem. Chem. Phys. 18 (2016) 13375- 13384.

[13] F. Geng, J. Liu, L. Zheng, L. Yu, Z. Li, G. Li, C. Tung, Micelle formation of long-chain imidazolium ionic liquids in aqueous solution measured by isothermal titration Microcalorimetry, J. Chem. Eng. Data. 55 (2010) 147-51.

[14] J. Łuczak, C. Jungnickel, M. Joskowska, J. Thöming, J. Hupka, Thermodynamics of micellization of imidazolium ionic liquids in aqueous solutions, J. Colloid Interface Sci. 336 (2009) 111-116.

[15] P. D. Galgano, O. A. El Seoud, Surface active ionic liquids: Study of the micellar properties of 1-1-alkyl]-3-methylimidazolium chlorides and comparison with structurally related surfactants, J. Colloid Interface. Sci. 361 (2011) 186-194. 
[16] J. L. Ferguson, J. D. Holbrey, S. Ng, N. V. Plechkova, K. R. Seddon, A. A. Tomaszowska, D. F. Wassell, A greener, halide-free approach to ionic liquid synthesis, Pure Appl. Chem. 84 (2011) 723-744.

[17] M. Benrraou, B. L. Bales, R. Zana, Effect of the nature of the counterion on the properties of anionic surfactants. 1. cmc, ionization degree at the $\mathrm{cmc}$ and aggregation number of micelles of sodium, cesium, tetramethylammonium, tetraethylammonium, tetrapropylammonium, and tetrabutylammonium dodecyl sulfates, J. Phys. Chem. B 107 (2003) 13432-13440.

[18] A. Kroflič, B. Šarac, J. Cerkovnik, M. Bešter-Rogač, Hydrophobicity of counterions as a driving force in the self-assembly process: Dodecyltrimethylammonium chloride and parabens, Colloid Surface A, 460 (2014) 108-117.

[19] L. Baranauskiene, V. Petrikaite, J. Matuliene, D. Matulis, Titration calorimetry standards and the precision of isothermal titration calorimetry data, Int. J. Mol. Sci. 10 (2009) 12752-2762.

[20] T. Wiseman, S. Williston, J. F. Brandts, L.-N. Lin, Rapid measurement of binding constants and heats of binding using a new titration calorimeter, Anal. Biochem. 179 (1989) 131-137.

[21] B. Šarac, M. Bešter-Rogač, Temperature and salt-induced micellization of dodecyltrimethylammonium chloride in aqueous solution: A thermodynamic study, J. Colloid Interface Sci. 338 (2009) 216-221.

[22] R. J. Hunter, Introduction to Modern Colloid Science, Oxford University Press, 1993.

[23] J. N. Phillips, The energetics of micelle formation, J. Trans. Soc. 51 (1954) 561-569.

[24] J. Lah, C. Pohar, G. Vesnaver, Calorimetric study of the micellization of alkylpyridinium and alkyltrimethylammonium bromides in water, J. Phys. Chem. B 104 (2000) 2522-2526. 
[25] J. Lah, M. Bešter-Rogač, T.-M. Perger, G. Vesnaver, Energetics in correlation with structural features: The case of micellization, J. Phys. Chem. B 110 (2006) 23279-23291.

[26] E. M. Woolley, T. E. Burchfield, Model for thermodynamics of ionic surfactant solutions. 2. Enthalpies, heat capacities, and volumes, J. Phys. Chem. 88 (1984) 2155-2163.

[27] W. H. Press, B. P. Flannery, S. A.Teukolsky, W. T. Vetterling, Numerical recipes, Cambridge University Press, Oxford, 1992.

[28] I. Drobnak, G. Vesnaver, J. Lah, Model-based thermodynamic analysis of reversible unfolding processes, J. Phys. Chem. 114 (2010) 8713-8722.

[29] A. Kroflič, B. Šarac, M. Bešter-Rogač, Thermodynamic characterization of CHAPS micellization ising isothermal titration calorimetry: Temperature, salt, and $\mathrm{pH}$ dependence, Langmuir 28 (2012) 10363-10371.

[30] A. Kroflič, B. Šarac, M. Bešter-Rogač, Influence of the alkyl chain length, temperature, and added salt on the thermodynamics of micellization: Alkyltrimethylammonium chlorides in $\mathrm{NaCl}$ aqueous solutions, J. Chem. Thermodyn. 43 (2011) 1557-1563.

[31] B. Šarac, G. Meriguet, A. Bernard, M. Bešter-Rogač, Salicylate isomer-specific effect on the micellization of dodecyltrimethylammonium chloride: Large effects from small changes, Langmuir 29 (2013) 4460-4469.

[32] T.-M. Perger, M. Bešter-Rogač, Thermodynamic of micelle formation of alkyltrimethylammonium chlorides from high performance electric conductivity measurements, J. Colloid Interface Sci. 313 (2007) 288-295.

[33] A. Kroflič, B. Šarac, M. Bešter-Rogač, What affects the degree of micelle ionization: Conductivty study of alkyltrimethylammonium chlorides, Acta Chim. Slov. 59 (2012) 564-570. 
[34] D. Ben-Amotz, Water-mediated hydrophobic interactions, Annu. Rev. Phys. Chem. 67 (2016) 617-638.

[35] R. Zielinski, Effect of temperature on micelle formation in aqueous nabr solutions of octyltrimethylammonium bromide, J. Colloid Interface Sci. 235 (2001) 201-209.

[36] R. Lumry, S. Rajender, S. Enthalpy-entropy compensation phenomena in water solutions of proteins and small molecules: A ubiquitous property of water, Biopolymers 9 (1970) 11251227.

[37] L.J Chen, S.-Y. Lin, C.-C. Huang, Effect of hydrophobic chain length of surfactants on enthalpy-entropy compensation of micellization, J. Phys. Chem. 102 (1998) 4350-4356.

[38] C. V. Krishnan, H. L. Friedman, Enthalpies of alkyl sulfonates in water, heavy water, and water-alcohol mixtures and the interaction of water with methylene groups, J. Solution Chem. 2 (1973) 37-51.

[39] C. V. Krishnan, H. L. Friedman, Studies of hydrophobic bonding in aqueous alcohols: Enthalpy measurements and model calculations, J. Solution Chem. 2 (1973) 119-140.

[40] C. Baar, R. Buchner, W. Kunz, Dielectric relaxation of cationic surfactants in aqueous solution. 2. Solute relaxation, J. Phys. Chem. B 105 (2001) 2914-2922.

[41] Z. Kiraly, I. Dekany, I. A thermometric titration study on the micelle formation of sodium decyl sulfate in water, J. Colloid Interface Sci. 242 (2001) 214-219.

[42] R. S. Spolar, J. R. Livingstone, M. T. Record Jr., Use of liquid hydrocarbon and amide transfer data to estimate contributions to thermodynamic functions of protein folding from the removal of nonpolar and polar surface from water, Biochemistry 31 (1992) 3947-3955. 
[43] L. J. Chen, Y.-H. Sheu, P.-J. Li, Heat capacity changes accompanying micelle formation upon burial of hydrophobic tail of nonionic surfactants, J. Phys. Chem. 108 (2004) 19096-19098.

[44] G. C. Kresheck, Isothermal titration calorimetry studies of neutral salt effects on the thermodynamics of micelle formation, J. Phys. Chem. B 113 (2009) 6732-6735.

[45] a) F. M. Richards, The interpretation of protein structures: total volume, group volume distributions and packing density. J. Mol. Biol. 82 (1974) 82, 1-14. b) F. M. Richards, Areas, volumes, packing and protein structure, Annu. Rev. Biophys. Bioeng. 6 (1977) 151-176. c) F. M. Richards, Calculation of molecular volumes and areas for structures of known geometry, Methods Enzymol. 115 (1985) 440-446.

[46] J. Gujt, J. M. Bešter-Rogač, E. Spohr, Structure and stability of long rod-like dodecyltrimethylammonium chloride micelles in solutions of hydroxybenzoates: A molecular, dynamics simulation study, Langmuir 32 (2016) 8275-8286.

[47] G. Singh, T. S. Kang, Micellization behavior of surface active ionic liquids having aromatic counterions in aqueous media, J. Phys. Chem. B 120 (2016) 1092-1105. 


\section{Thermodynamic Study for Micellization of Imidazolium Based Surface Active Ionic Liquids in Water: Effect of Alkyl Chain Length and Anions}

Bojan Šarac $^{\mathrm{a}}, \check{Z ̆}_{\text {iga Medoš }}^{\mathrm{a}}$, Alice Cognigni ${ }^{\mathrm{b}}$, Katharina Bica $^{\mathrm{b}, *}$, Li-Jen Chen $^{\mathrm{c}}$, Marija Bešter-Rogač ${ }^{a}$ *

${ }^{a}$ Faculty of Chemistry and Chemical Technology, University of Ljubljana, Večna pot 113, SI-1000 Ljubljana, Slovenia

${ }^{\mathrm{b}}$ Institute of Applied Synthetic Chemistry, Vienna University of Technology Getreidemarkt 9/163, A-1060 Vienna, Austria

${ }^{c}$ Department of Chemical Engineering, National Taiwan University, Taipei 10617, Taiwan

*Corresponding authors:

Katharina Bica

Institute of Applied Synthetic Chemistry, Vienna University of Technology Getreidemarkt $9 / 163$

A-1060 Vienna, Austria

katharina.schroeder@tuwien.ac.at

Marija Bešter-Rogač

Faculty of Chemistry and Chemical Technology, Večna pot 113, University of Ljubljana, SI1000 Ljubljana, Slovenia

marija.bester@fkkt.uni-lj.si

Supplementary Material

Content of Supplementary Material 


\section{Thermodynamic analysis}

Fig. S1. Temperature dependent enthalpograms for investigated SAILs in water. Solid lines represent the global fits according to the Eqs. (m-t).

Fig. S2. Temperature dependence of $\mathrm{cmc}$ for investigated SAILs in water. Solid lines represent the corresponding polynomial fits, $\mathrm{cmc}=\mathrm{A}+\mathrm{B} T+\mathrm{C} T^{2}$. Coefficients are given in Table $\mathrm{S} 2$ in Supporting Information.

Fig. S3. Temperature dependence of the standard enthalpy of micellization, $\Delta_{\mathrm{M}} H^{0}$, for investigated SAILs in water. Solid lines represent the corresponding linear fits,

Fig. S4. Enthalpy-entropy compensation plots for the micellization process of investigated SAILs in water. Solid lines represent linear fits (Eq. (11) in main manuscript).

Fig. S5. Correlation between $\Delta_{\mathrm{M}} c_{\mathrm{p}}^{0}$ and $\beta$ for the micellization process of investigated $\left[\mathrm{C}_{12} \mathrm{mim}\right] \mathrm{X}$ SAILs in water.

Fig. S6. Viscosities of aqueous solutions of investigated $\left[\mathrm{C}_{12} \mathrm{mim}\right] \mathrm{X}$ SAILs at 298.15 K.

Table S1: Thermodynamic parameters of micellization for investigated SAILs in water at all the investigated temperatures: critical micelle concentration, $\mathrm{cmc}$, degree of micelle ionization, $\beta$, standard enthalpy, $\Delta_{\mathrm{M}} H^{0}$, Gibbs free energy, $\Delta_{\mathrm{M}} G^{0}$, and entropy contributions, $T \Delta_{\mathrm{M}} S^{0}$, for micellization for investigated systems in water as obtained by the fitting procedure.

Table S2. Coefficients of polynomials $\mathrm{cmc}=\mathrm{A}+\mathrm{B} T+\mathrm{C} T^{2 a}$. 


\section{Thermodynamic analysis}

a) Model description. According to the mass-action model [1-4] the micellization process of a cationic surfactant at constant temperature, $T$, and pressure, $p$, may be described as

$$
n \mathrm{~S}^{+}+(n-z) \mathrm{C}^{-} \rightleftarrows \mathrm{M}^{z}
$$

where $\mathrm{S}^{+}$represents the monomeric state of surfactant, $\mathrm{C}^{-}$corresponding counterions and $\mathrm{M}^{\mathrm{p}+}$ the micellar aggregate of $n$ surfactant monomers with an effective charge of $z$. The equilibrium between species can be expressed by equilibrium constant, $\mathrm{K}$, as

$$
K=\frac{a_{\mathrm{M}}}{a_{\mathrm{S}}^{n} a_{\mathrm{C}}^{n-z}}=\frac{m_{\mathrm{M}} / m^{0}}{\left(m_{\mathrm{S}} / m^{0}\right)^{n}\left(m_{\mathrm{C}} / m^{0}\right)^{n-z}} \cdot \frac{\gamma_{\mathrm{M}}}{\gamma_{\mathrm{S}}^{n} \gamma_{\mathrm{C}}^{n-z}}=K_{\mathrm{M}} \cdot K_{\gamma}
$$

where $a_{\mathrm{S}}, a_{\mathrm{C}}$ and $a_{\mathrm{M}}$ are the activities of the surfactant ions in monomeric form, counterions and micelles, respectively; $m_{\mathrm{S}}, m_{\mathrm{C}}$ and $m_{\mathrm{M}}$ are the corresponding molalities; $\gamma_{\mathrm{S}}, \gamma_{\mathrm{C}}$ and $\gamma_{\mathrm{M}}$ the corresponding activity coefficients and $m^{0}$ standard molality, $1 \mathrm{~mol} \mathrm{~kg}{ }^{-1}$.

At low concentrations of surfactant it can be assumed that $K_{\gamma} \approx 1$, and the apparent equilibrium constant, $K_{M}$, usually is written in a simplified form as

$$
K_{\mathrm{M}}=\frac{m_{\mathrm{M}}}{m_{\mathrm{S}}^{n} m_{\mathrm{C}}^{n-z}}
$$

Surfactant solution with concentration greater than $\mathrm{cmc}$ can be considered as a mixed electrolyte solution with the total surfactant molality, $m$,

$$
m=m_{\mathrm{S}}+n \cdot m_{\mathrm{M}}
$$

and the degree of micellization $\alpha_{\mathrm{M}}=n \cdot m_{\mathrm{M}} / m$. The total molality of counterions, $m_{\mathrm{C}}$, is given as

$$
m_{\mathrm{C}}=m-(n-z) m_{\mathrm{M}}
$$

From the above equations it follows that the standard Gibbs free energy for micellization, $\Delta_{\mathrm{M}} G^{0}$, of ionic surfactant can be expressed as

$$
\Delta_{\mathrm{M}} G^{0}=-\frac{R T}{n} \ln K_{\mathrm{M}}=-\frac{R T}{n} \ln \left(\frac{\alpha_{\mathrm{M}} m^{1-n}}{n\left(1-\alpha_{\mathrm{M}}\right)^{n}\left(m\left(1-\alpha_{\mathrm{M}}(1-\beta)\right)\right)^{n-z}}\right)
$$


where $\beta$ is degree of micelle ionization $(=z / n$, where $z$ is the effective charge of the micelles and $n$ is the number of surfactant monomer in the micellar aggregate).

b) Connection of model to experiment. The equilibrium between monomeric surfactant ions, their micelles and corresponding simple counterions can be also described in terms of the composition variables $n_{1}$ (the number of moles of solvent), $n_{\mathrm{S}}$ (the number of moles of surfactant ions in monomeric form), $n_{\mathrm{C}}$ (the number of moles of free counterions), and $n_{\mathrm{M}}$ (the number of moles of surfactant ions in micellar form) and the corresponding partial molar enthalpies $\bar{H}_{1}, \bar{H}_{\mathrm{S}}, \bar{H}_{\mathrm{C}}$, and $\bar{H}_{\mathrm{M}}$. The enthalpy of solution in the titration cell obtained after i-th injection, $H_{\mathrm{i}}$, can be thus expressed as

$H_{\mathrm{i}}=n_{1} \bar{H}_{1}+n_{2} \bar{H}_{2}=n_{1} \bar{H}_{1}+n_{\mathrm{S}} \bar{H}_{\mathrm{S}}+n_{\mathrm{C}} \bar{H}_{\mathrm{C}}+n_{\mathrm{M}} \bar{H}_{\mathrm{M}}$

By taking into account the total number of moles of surfactant, $n_{2}=n_{\mathrm{S}}+n_{\mathrm{M}}$, and counterions, $n_{\mathrm{C}}=n_{\mathrm{S}}+(z / n) n_{\mathrm{M}}$, Eq. $(\mathrm{g})$ becomes

$H_{\mathrm{i}}=n_{1} \bar{H}_{1}+n_{2}\left(\bar{H}_{\mathrm{S}}+\bar{H}_{\mathrm{C}}\right)+n_{\mathrm{M}} \Delta_{\mathrm{M}} H$

where the enthalpy of micelle formation, $\Delta_{\mathrm{M}} H$, is defined as

$$
\Delta_{\mathrm{M}} H=\left(\bar{H}_{\mathrm{M}}-\bar{H}_{\mathrm{S}}-(1-z / n) \bar{H}_{\mathrm{C}}\right)
$$

By taking the partial derivative of enthalpy, $H_{\mathrm{i}}$, with respect to $n_{2}$ at constant $p, T$, and $n_{1}$ and using the Gibbs-Duhem equation $\left(\sum_{\mathrm{i}} n_{\mathrm{i}} \mathrm{d} \bar{H}_{\mathrm{i}}=0, p, T=\right.$ const. $)$ we obtain

$$
\begin{aligned}
& \bar{H}_{2}=\left(\frac{\partial H_{\mathrm{i}}}{\partial n_{2}}\right)_{p, T, n_{1}}= \\
& =\frac{\partial n_{1}}{\partial n_{2}} \bar{H}_{1}+n_{1} \frac{\partial \bar{H}_{1}}{\partial n_{2}}+\frac{\partial n_{2}}{\partial n_{2}}\left(\bar{H}_{\mathrm{S}}+\bar{H}_{\mathrm{C}}\right)+n_{2} \frac{\partial\left(\bar{H}_{\mathrm{S}}+\bar{H}_{\mathrm{C}}\right)}{\partial n_{2}}+\frac{\partial n_{\mathrm{M}}}{\partial n_{2}} \Delta_{\mathrm{M}} H+n_{\mathrm{M}} \frac{\partial \Delta_{\mathrm{M}} H}{\partial n_{2}}
\end{aligned}
$$

which gives us the relation below

$$
\bar{H}_{2}=\left(\bar{H}_{\mathrm{S}}+\bar{H}_{\mathrm{C}}\right)+\Delta_{\mathrm{M}} H\left(\frac{\partial n_{\mathrm{M}}}{\partial n_{2}}\right)_{n_{1}, p, T} .
$$


In the ITC experiment (constant $p, T$ ), the measured property reflects heat effect, $q_{\mathrm{i}}$, that results from each (i-th) injection of the titrant solution into the titration cell. The measured heat effect is thus usually given as the enthalpy change, $\Delta H$, expressed per mole of added titrant (solute)

$$
\Delta H=\frac{q_{\mathrm{i}}}{\Delta n_{2}}=\frac{\left(H_{\mathrm{i}}-H_{\mathrm{i}-1}\right)}{\Delta n_{2}}-\frac{H_{\mathrm{a}}}{\Delta n_{2}}
$$

where $H_{\mathrm{i}}$ and $H_{\mathrm{i}-1}$ represent the enthalpies of solution in measuring cell after $\mathrm{i}$-th and (i-1)-th injection, respectively. $H_{\mathrm{a}}$ is the enthalpy of injected aliquot of titrant solution and $\Delta n_{2}$ is the amount of solute in that aliquot. As during the titration procedure the aliquots are constant and very small ( $\Delta n_{2}<<n_{1}=$ amount of solvent in the titration cell), the Eq. (l) simplifies into

$\Delta H=\left(\frac{\partial H}{\partial n_{2}}\right)_{n_{1}, p, T}-$ const $=\bar{H}_{2}-$ const.

The combination of Eqs. (k) and (m) leads to the measured relative molar enthalpy, $\Delta H$, containing the enthalpy of micellization which is assumed to be concentration independent and thus equal to its value in the standard state $\left(\Delta_{\mathrm{M}} H=\Delta_{\mathrm{M}} H^{0}\right)$.

$$
\Delta H=\left(\bar{H}_{\mathrm{S}}+\bar{H}_{\mathrm{C}}-\mathrm{const}\right)+\Delta_{\mathrm{M}} H^{0}\left(\frac{\partial n_{\mathrm{M}}}{\partial n_{2}}\right)_{n_{1}, p, T} .
$$

Using the Gibbs-Helmholtz relation and the Guggenheim approximation for surfactant mean activity coefficient ${ }^{3,5}$

$$
-\log \gamma_{ \pm}=\frac{A_{(T)} \sqrt{m}}{1+\sqrt{m}}+B_{(T)} m
$$

below the cmc $\left(\bar{H}_{\mathrm{S}}+\bar{H}_{\mathrm{C}}\right)$ contribution can be expressed as

$$
\bar{H}_{\mathrm{C}}+\bar{H}_{\mathrm{S}}=\bar{H}_{2}^{0}+2 \cdot R T^{2}\left(\frac{A_{(T)}^{\prime} \sqrt{m}}{1+\sqrt{m}}+B_{(T)}^{\prime} m\right)
$$

where $\bar{H}_{2}^{0}$ represents the partial molar enthalpy of surfactant in its standard state. The coefficients $A_{(T)}^{\prime}$ and $B_{(T)}^{\prime}$ are temperature derivatives of the constants $A_{(T)}$ and $B_{(T)}$, that reflect solvent properties and ion-ion interactions, respectively [5]. 
Above the cmc, $\left(\bar{H}_{\mathrm{S}}+\bar{H}_{\mathrm{C}}\right)$ contribution is assumed to remain constant and equal to its value at the cmc due to the small changes in concentrations of $\mathrm{S}^{+}$and $\mathrm{C}^{-}$ions.

The $\left(\partial n_{\mathrm{M}} / \partial n_{2}\right)_{n_{1}, p, T}$ derivative in the Eq. (n) represents the fraction of surfactant molecules in micellar state $\mathrm{M}$ and can be derived from the apparent equilibrium constant, $K_{\mathrm{M}}$, (Eqs. (c) and (f)) as

$\left(\frac{\partial n_{\mathrm{M}}}{\partial n_{2}}\right)_{n_{1}, p, T}=\frac{n[u+g]}{1+n[u+(1-\beta) g]}$

where the parameters $u$ and $g$ are functions of the degree of micellization $\left(\alpha_{\mathrm{M}}\right)$ and the degree of micelle ionization $(\beta)$

$$
\begin{aligned}
& u=\frac{\alpha_{\mathrm{M}}}{1-\alpha_{\mathrm{M}}}, \\
& g=\frac{(1-z / n) \alpha_{\mathrm{M}}}{1-(1-z / n) \alpha_{\mathrm{M}}+m_{x} / m} .
\end{aligned}
$$

c) Fitting procedure. In the global analysis (fitting of experimental curves at all temperatures simultaneously) of ITC data we used the Kirchhoff's law

$\Delta_{\mathrm{M}} H^{0}(T)=\Delta_{\mathrm{M}} H^{0}\left(T_{\mathrm{r}}\right)+\Delta_{\mathrm{M}} c_{p}^{0}\left(T-T_{\mathrm{r}}\right)$

and the integrated Gibbs-Helmholtz equation

$$
\Delta_{\mathrm{M}} G^{0}(T)=T\left(\Delta_{\mathrm{M}} G^{0}\left(T_{\mathrm{r}}\right) / T_{\mathrm{r}}+\Delta_{\mathrm{M}} H^{0}\left(T_{\mathrm{r}}\right)\left[1 / T-1 / T_{\mathrm{r}}\right]+\Delta_{\mathrm{M}} c_{p}^{0}\left[1-T_{\mathrm{r}} / T-\ln \left(T / T_{\mathrm{r}}\right)\right]\right)(\mathrm{t})
$$

where $\Delta_{\mathrm{M}} H^{0}\left(T_{\mathrm{r}}\right)$ and $\Delta_{\mathrm{M}} G^{0}\left(T_{\mathrm{r}}\right)$ are the standard enthalpy and the standard Gibbs free energy of micellization at some reference temperature $T_{\mathrm{r}}$. Therefore, it follows from the Eq. (f) and Eqs. (o-t), that the ITC model equation (Eq. (n)) may be described in terms of $n, \Delta_{\mathrm{M}} H^{0}, \Delta_{\mathrm{M}} G^{0}$, $\Delta_{\mathrm{M}} c_{p}^{0}$, and the coefficients $A_{(T)}^{\prime}$ and $B_{(T)}^{\prime}$ at any surfactant concentration and temperature, $T$. All these values were obtained by fitting of the model equation to the experimental data points in the following manner. The model equation was compared to the experimental curves via the $\chi^{2}$ function defined as 


$$
\chi^{2}=\sum_{i}\left(\frac{\Delta H_{\mathrm{i}}-\Delta H_{\mathrm{i}}^{\mathrm{mod}}}{\Delta\left(\Delta H_{\mathrm{i}}\right)}\right)^{2}
$$

where $\Delta H_{\mathrm{i}}$ and $\Delta H_{\mathrm{i}}^{\text {mod }}$ represent the experimental and the model enthalpy, whereas $\Delta\left(\Delta H_{\mathrm{i}}\right)$ represents the absolute error in measured enthalpy, $\Delta H_{\mathrm{i}}$. By minimization of $\chi^{2}$ function best-fit values of the above-mentioned parameters were calculated using the Levenberg-Marquardt nonlinear regression algorithm [6]. Their values were further used to calculate corresponding $\Delta_{\mathrm{M}} H^{0}, \Delta_{\mathrm{M}} G^{0}$, and $T \Delta_{\mathrm{M}} S^{0}$ at some other temperature. The entropy change, $\Delta_{\mathrm{M}} S^{0}$, associated with the examined process was obtained from the GibbsHelmholtz equation

$$
\Delta_{\mathrm{M}} S^{0}=\frac{\Delta_{\mathrm{M}} H^{0}-\Delta_{\mathrm{M}} G^{0}}{T}
$$

and the molar heat capacity change of micelle formation, $\Delta_{\mathrm{M}} c_{p}^{0}$, was given from the temperature dependence of $\Delta_{\mathrm{M}} H^{0}$.

d) Fitting algorithm. Modeling algorithm of fitting of model function (Eq. (n)) to the corresponding experimental data (Fig. 1 in the main manuscript and S1 in Supplementary material) was following:

1. At a given $T_{\mathrm{r}}$ (usually $298.15 \mathrm{~K}$ ) reasonable initial values of adjustable parameters $n$, $\Delta_{\mathrm{M}} H^{0}\left(T_{\mathrm{r}}\right), \Delta_{\mathrm{M}} G^{0}\left(T_{\mathrm{r}}\right), \Delta_{\mathrm{M}} c_{p}^{0}$, and the coefficients $A^{\prime}(T)$ and $B_{(T)}^{\prime}$ are chosen.

2. For a given $\Delta_{\mathrm{M}} G^{0}\left(T_{\mathrm{r}}\right)$ value $\alpha_{\mathrm{M}}$ can be determined at any concentration $m$ iteratively from Eq.(f) together with the corresponding derivative , $\left(\partial n_{\mathrm{M}} / \partial n_{2}\right)_{n 1, p, T}$ (Eq. (q)).

3. The value of the model function (Eq. (n)) at a given titration point $(m)$ is calculated for the selected set of adjustable parameters. 
4. Using Kirchhoff's law and the integrated Gibbs-Helmholtz (Eqs. (s) and (t)) the $\Delta_{\mathrm{M}} G^{0}$ and $\Delta_{\mathrm{M}} H^{0}$ are calculated for other temperatures.

5. Steps 2, 3 are repeated for every experimental point (each successive $m$ ) to calculate the corresponding model functions (Eq.(n)).

6. The model functions (Eq. (n)) are compared to the corresponding experimental curves via the $\chi^{2}$ function defined as:

$\chi^{2}=\sum_{i}\left(\frac{\Delta H_{\mathrm{i}}-\Delta H_{\mathrm{i}}^{\mathrm{mod}}}{\Delta\left(\Delta H_{\mathrm{i}}\right)}\right)^{2}$

where $\Delta H_{\mathrm{i}}$ is the experimental $\Delta H$ at given titration point $(m), \Delta H_{\mathrm{i}}^{\text {mod }}$ is the corresponding value of the model function (Eq. (n)) and $\Delta\left(\Delta H_{\mathrm{i}}\right)$ is the estimated absolute error in the measured $\Delta H$ (ITC).

7. The best fit of the model functions to the corresponding experimental curves ( $\Delta H$ vs. $m$ ) is obtained by minimization of the corresponding $\chi^{2}$. Levenberg-Marquardt algorithm is applied to select new sets of adjustable parameters $n, \Delta_{\mathrm{M}} H^{0}\left(T_{\mathrm{r}}\right), \Delta_{\mathrm{M}} G^{0}\left(T_{\mathrm{r}}\right), \Delta_{\mathrm{M}} c_{p}^{0}$, and the coefficients $A_{(T)}^{\prime}$ and $B_{(T)}^{\prime}$ (ITC at given $T$ ) and by repeating steps 1 . to 6 . to find a minimum in $\chi^{2}$. Their values at the global minimum of $\chi^{2}$ are considered as the best descriptors of the experimental ITC curves.

\section{Statistical analysis:}

(i) The mean-square deviations (errors) of the adjustable parameters are calculated as square roots of the diagonal elements, $c_{\mathrm{kl}}$, of the variance-covariance matrix, $\boldsymbol{C}$, which is defined as the inverse of the curvature matrix, $\beta$. The elements of the curvature matrix, $\beta_{\mathrm{kl}}$, are given by the simplified relation $[7,8]$ :

$$
\beta_{\mathrm{kl}}=\frac{\partial^{2} \chi^{2}}{\partial B_{\mathrm{k}} \partial B_{1}} \cong \sum_{\mathrm{i}} \frac{1}{\left(\Delta\left(\Delta H_{\mathrm{i}}\right)\right)^{2}}\left(\frac{\partial \Delta H_{\mathrm{i}}^{\mathrm{mod}}}{\partial B_{\mathrm{k}}} \frac{\partial \Delta H_{\mathrm{i}}^{\mathrm{mod}}}{\partial B_{1}}\right)
$$


in which $B_{\mathrm{k}}$ and $B_{1}$ are the adjustable parameters $\left(n, \Delta_{\mathrm{M}} H^{0}\left(T_{\mathrm{r}}\right), \Delta_{\mathrm{M}} G^{0}\left(T_{\mathrm{r}}\right), \Delta_{\mathrm{M}} c_{p}^{0}\right.$, and the coefficients $A_{(T)}^{\prime}$ and $\left.B_{(T)}^{\prime}\right)$. The derivatives in Eq. (x) are calculated analytically.

In this work, only the global fitting of the model equation to the corresponding experimental curves at all the examined temperatures was carried out simultaneously. The advantage of this procedure over the individual fitting at a single temperature is greater confidence in the proposed model and consequently in all the adjustable parameters [9]. The main presumption concerning the global fitting was temperature independence of the aggregation number. But in our previous work it turned out that values obtained from the individual best-fit values and the global-fit value for $n$ of the chosen system were basically the same [10].

Degree of micelle ionization was assumed to be also temperature independent for all the systems investigated. During the fitting procedure, anomalies from purely sigmoidal behavior at some titration curves were observed $\left(\left[\mathrm{C}_{10} \mathrm{mim}\right] \mathrm{Cl}\right.$ at higher temperatures, $\left[\mathrm{C}_{12} \mathrm{mim}\right] \mathrm{OMs}$ at $288.15 \mathrm{~K}$ and at $308.15 \mathrm{~K},\left[\mathrm{C}_{12} \mathrm{mim}\right] \mathrm{OAc}$ at $288.15 \mathrm{~K}$ and at $\left.\left.298.15 \mathrm{~K}\right]\right)$.

All obtained thermodynamic parameters are gathered in Tables 1 and 2 in the main text and in Table S1 in Supporting Information. 

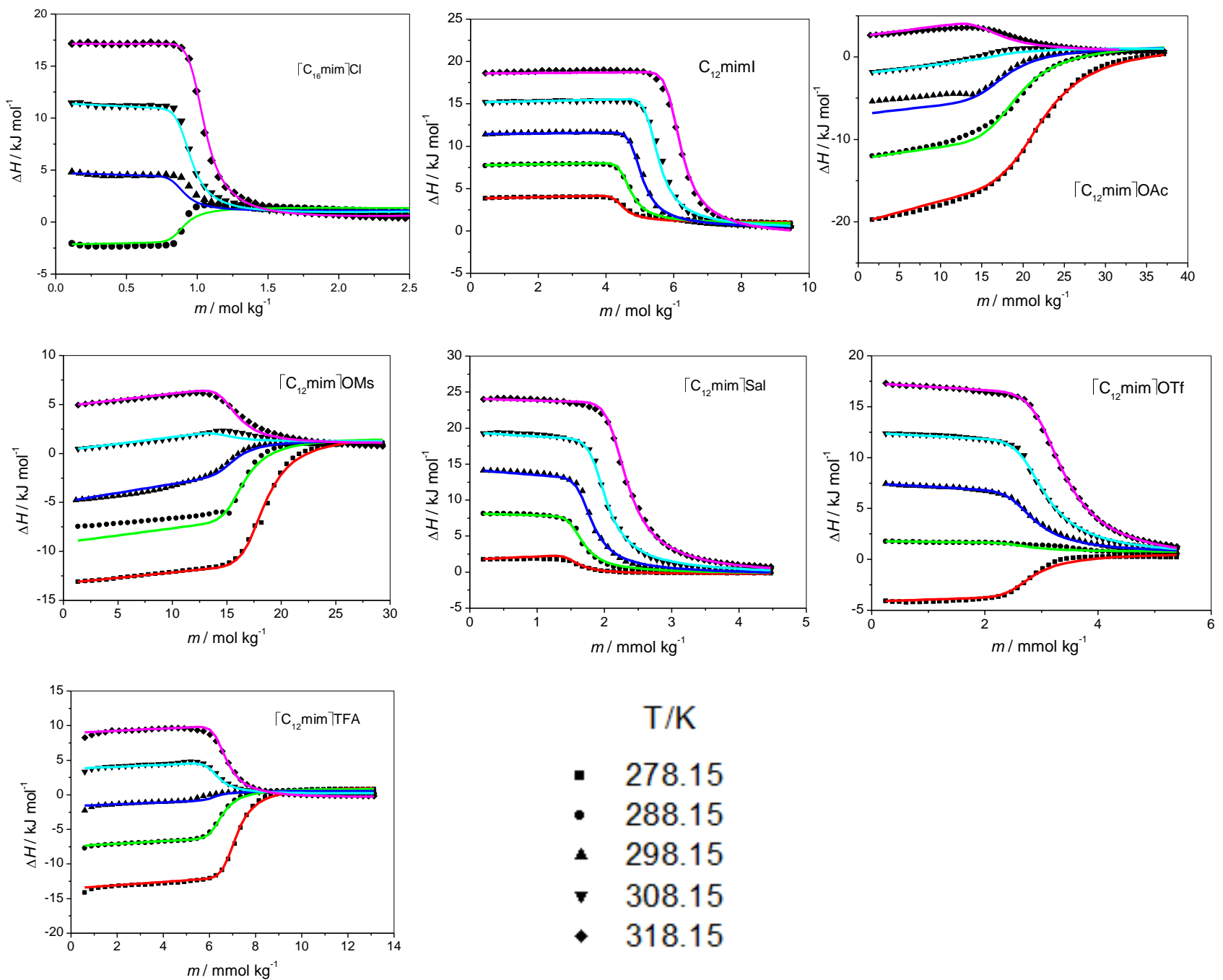

\section{$\mathrm{T} / \mathrm{K}$}

- 278.15

- 288.15

- 298.15

- 308.15

- 318.15
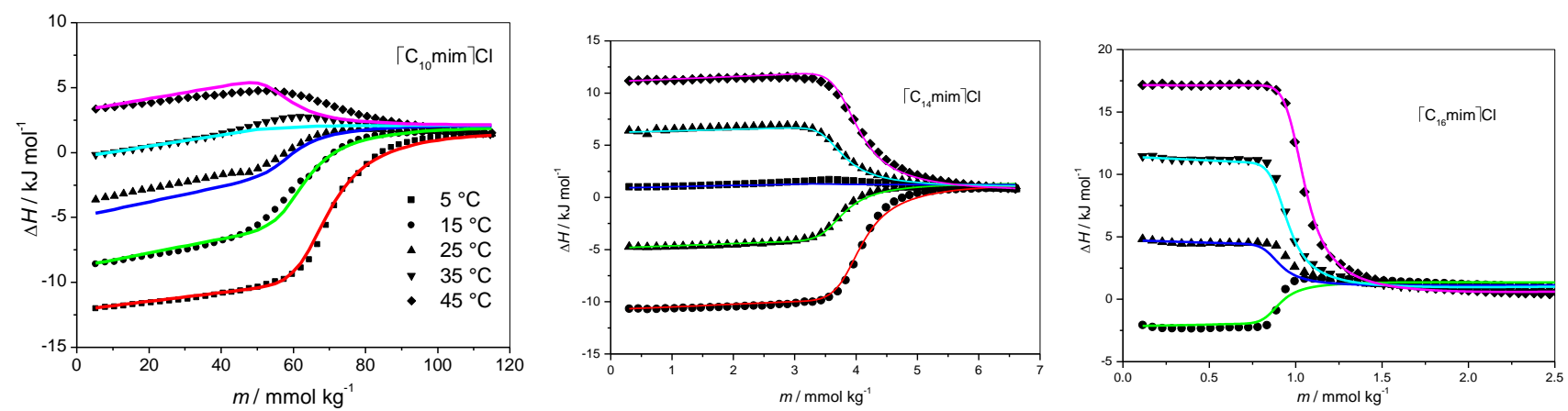

Fig. S1. Temperature dependent enthalpograms for investigated SAILs in water. Solid lines represent the global fits according to the Eqs.( $\mathrm{n}-\mathrm{t})$. 

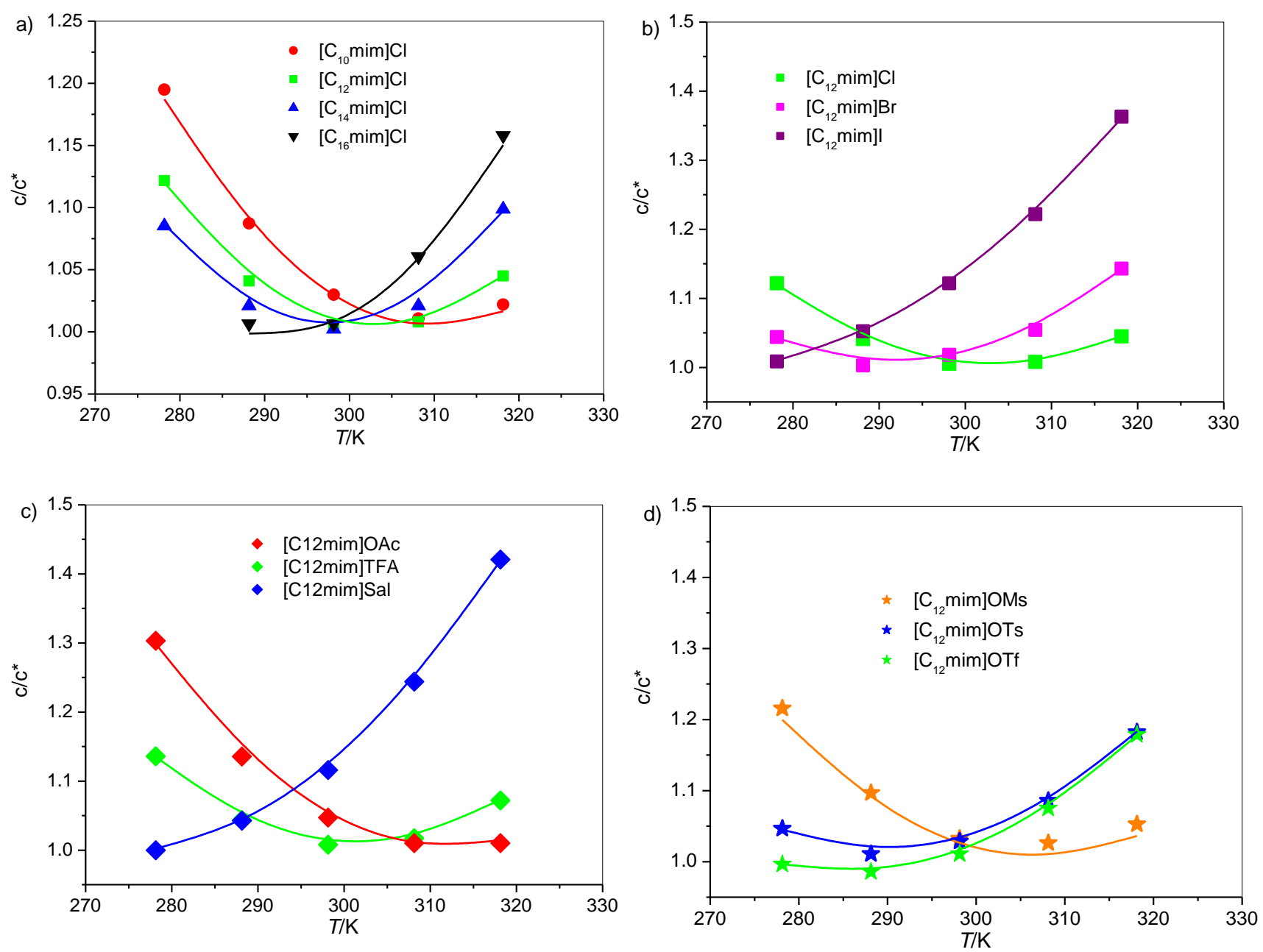

Fig. S2. Temperature dependence of $\mathrm{cmc}$ for investigated SAILs in water. Solid lines represent the corresponding polynomial fits, $\mathrm{cmc}=\mathrm{A}+\mathrm{B} T+\mathrm{C} T^{2}$. Coefficients are given in Table S2 in Supplementary material. 

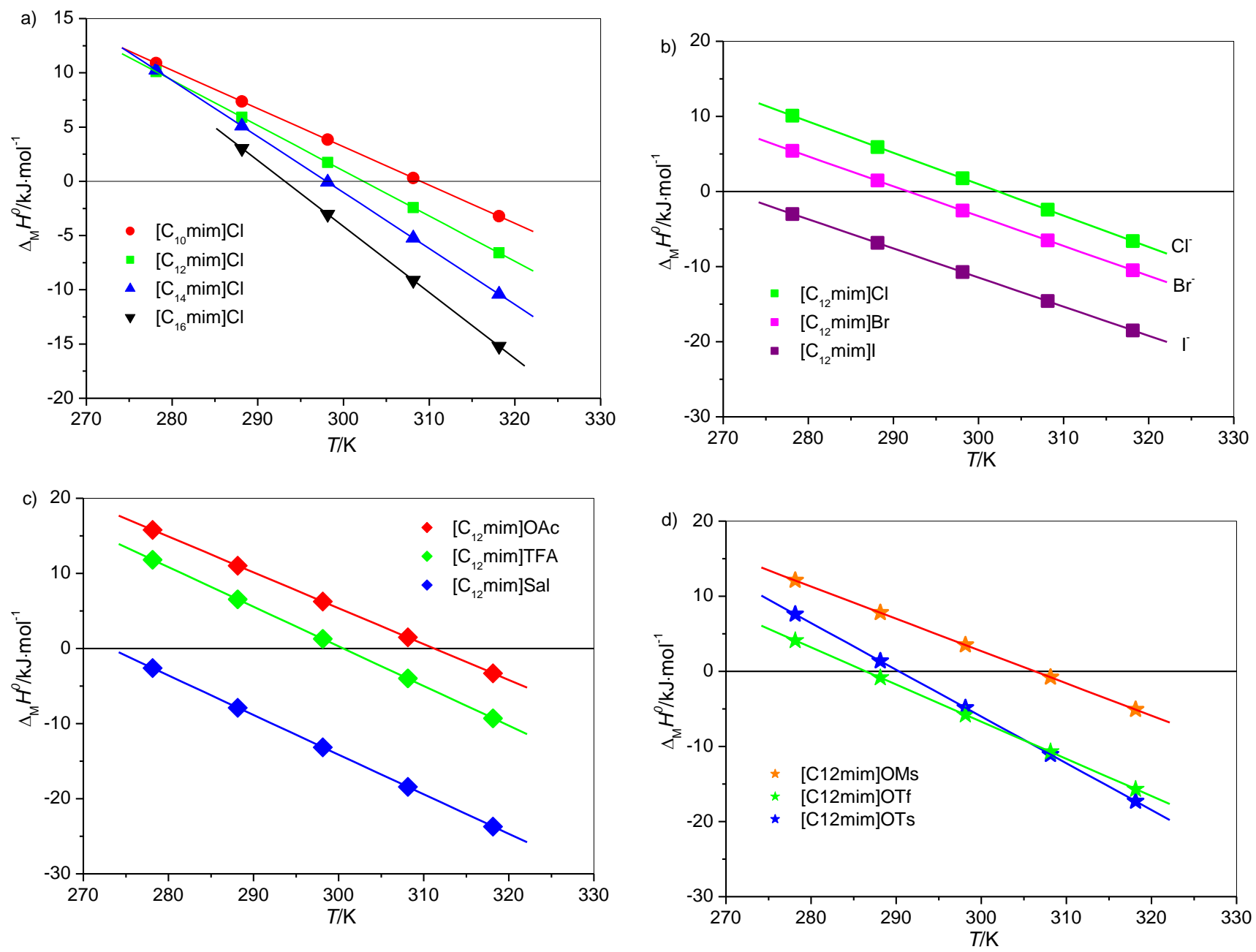

Fig. S3. Temperature dependence of the standard enthalpy of micellization, $\Delta_{\mathrm{M}} H^{0}$, for investigated SAILs in water. Solid lines represent the corresponding linear fits. 

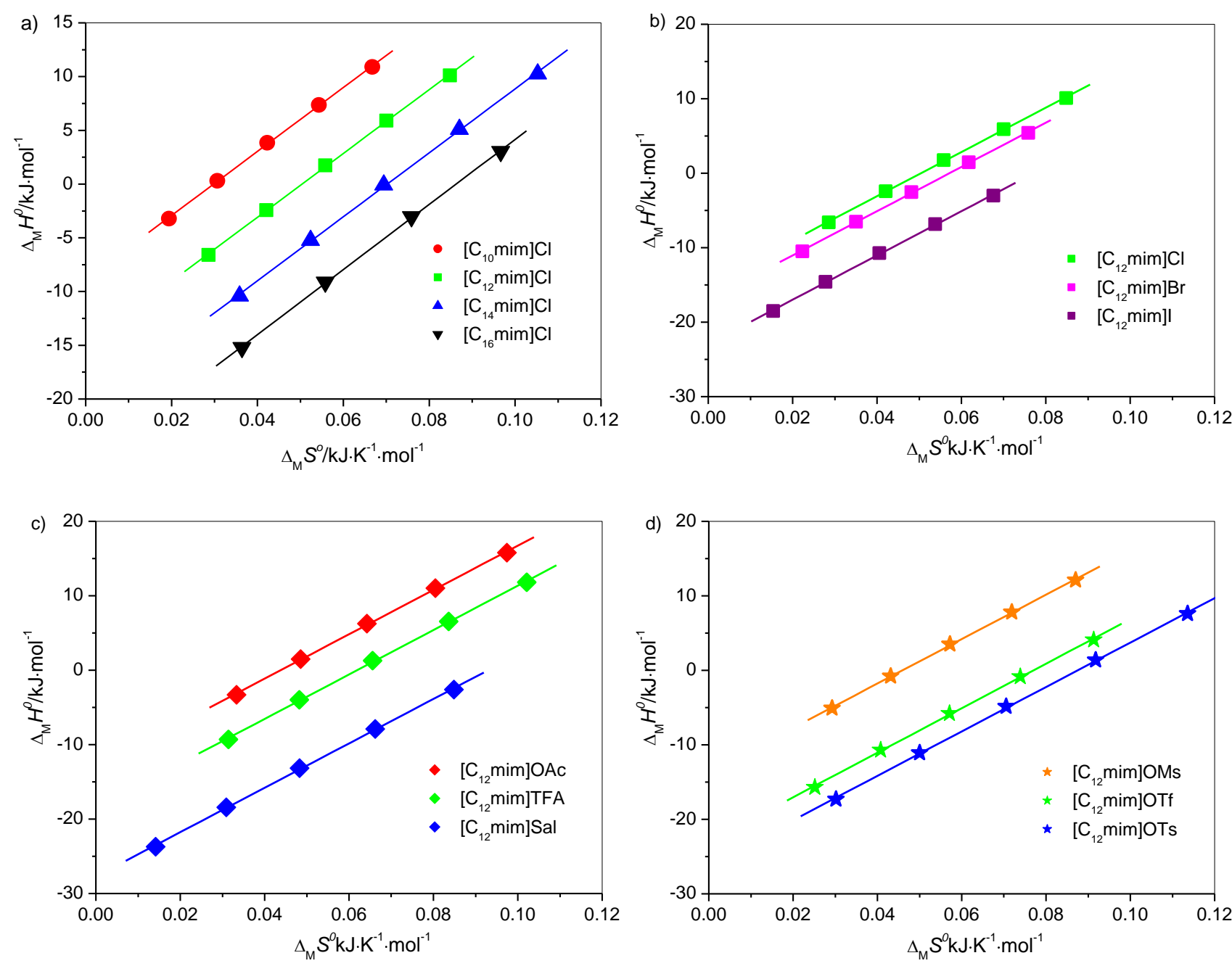

Fig. S4. Enthalpy-entropy compensation plots for the micellization process of investigated SAILs in water. Solid lines represent linear fits (Eq. (11) in main manuscript). 


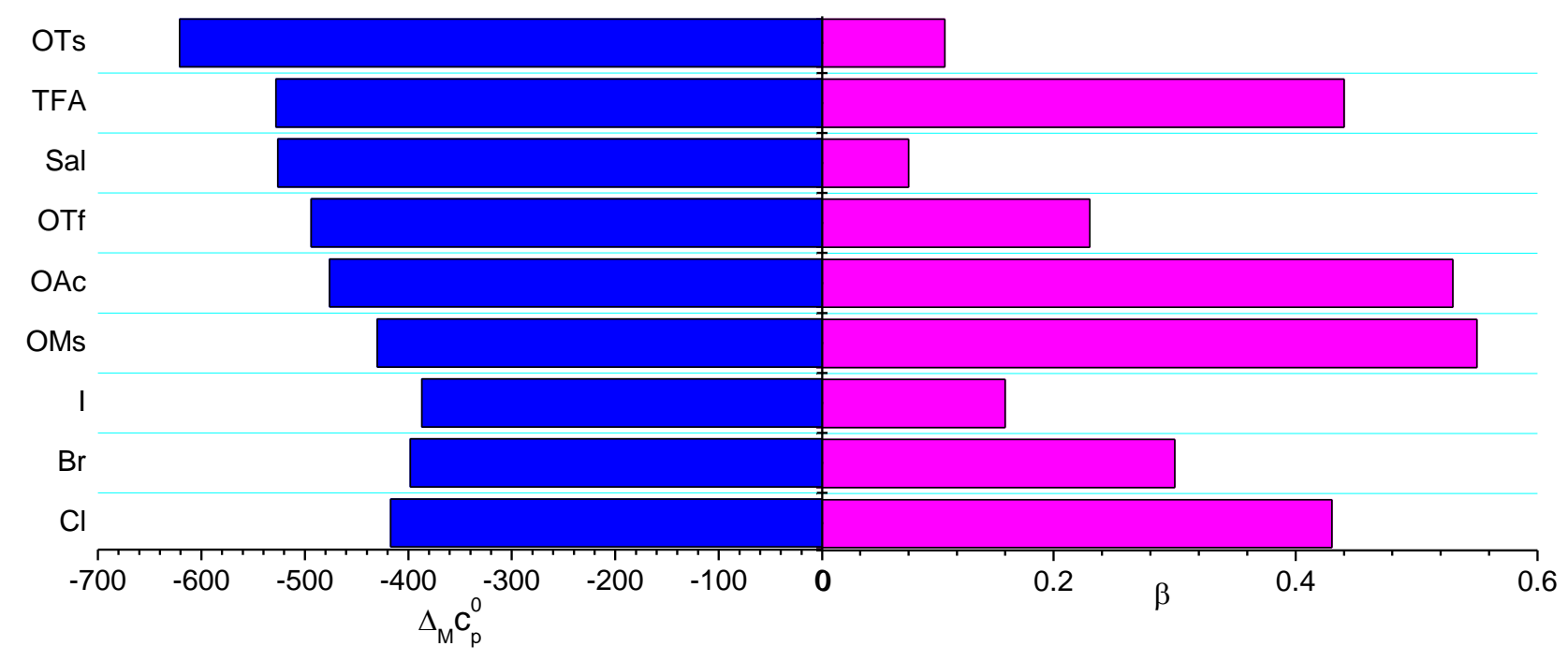

Fig. S5. Correlation between $\Delta_{\mathrm{M}} c_{\mathrm{p}}^{0}$ and $\beta$ for the micellization process of investigated $\left[\mathrm{C}_{12} \mathrm{mim}\right] \mathrm{X}$ SAILs in water.

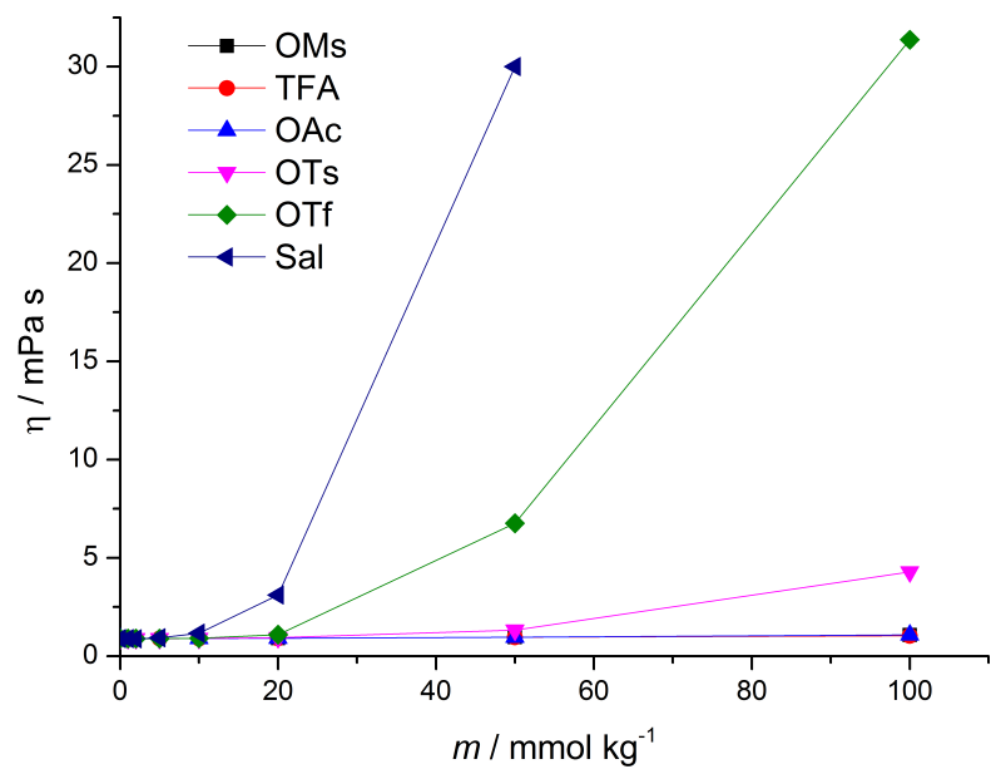

Fig. S6. Viscosities of aqueous solutions of investigated $\left[\mathrm{C}_{12} \mathrm{mim}\right] \mathrm{X}$ SAILs at $298.15 \mathrm{~K}$. 
Table S1: Thermodynamic parameters of micellization for investigated SAILs in water at all the investigated temperatures: critical micelle concentration, cmc, degree of micelle ionization, $\beta$, standard enthalpy, $\Delta_{\mathrm{M}} H^{0}$, Gibbs free energy, $\Delta_{\mathrm{M}} G^{0}$, and entropy contributions, $T \Delta_{\mathrm{M}} S^{0}$, for micellization for investigated systems in water as obtained by the fitting procedure and comparison with literature data (where possible). ${ }^{\mathrm{a}, \mathrm{b}}$

\begin{tabular}{|c|c|c|c|c|c|}
\hline$T$ & $\mathrm{cmc}$ & $\beta^{c}$ & $\Delta_{\mathrm{M}} H^{0}$ & $\Delta_{\mathrm{M}} G^{0}$ & $T \Delta_{\mathrm{M}} S^{0}$ \\
\hline \multicolumn{6}{|c|}{$\left[\mathrm{C}_{10} \mathrm{mim}\right] \mathrm{Cl}$} \\
\hline 278.15 & $70 \pm 2$ & & $10.89 \pm 0.09$ & $-7.684 \pm 0.006$ & $18.57 \pm 0.09$ \\
\hline 288.15 & $63 \pm 2$ & & $7.36 \pm 0.08$ & $-8.289 \pm 0.005$ & $15.65 \pm 0.08$ \\
\hline 298.15 & $\begin{array}{c}60 \pm 2 \\
58.5 \pm 1.3^{\mathrm{d}} \\
61.83^{\mathrm{e}}\end{array}$ & $0.54 \pm 0.02$ & $\begin{array}{c}3.83 \pm 0.09 \\
3.5 \pm 0.2^{\mathrm{d}}\end{array}$ & $-8.771 \pm 0.006$ & $12.61 \pm 0.09$ \\
\hline 308.15 & $59 \pm 2$ & & $0.31 \pm 0.12$ & $-9.136 \pm 0.009$ & $9.4 \pm 0.1$ \\
\hline 318.15 & $59 \pm 2$ & & $-3.2 \pm 0.2$ & $-9.39 \pm 0.01$ & $6.2 \pm 0.2$ \\
\hline \multicolumn{6}{|c|}{$\left[\mathrm{C}_{12} \mathrm{mim}\right] \mathrm{Cl}$} \\
\hline 278.15 & $17.0 \pm 0.9$ & & $10.1 \pm 0.1$ & $-13.493 \pm 0.008$ & $23.6 \pm 0.1$ \\
\hline 288.15 & $15.8 \pm 0.8$ & & $5.91 \pm 0.07$ & $-14.267 \pm 0.007$ & $20.18 \pm 0.08$ \\
\hline 298.15 & $\begin{array}{c}15.2 \pm 0.8 \\
14.53^{\mathrm{c}} \\
14.23^{\mathrm{e}}\end{array}$ & $0.43 \pm 0.01$ & $1.74 \pm 0.06$ & $-14.896 \pm 0.006$ & $16.64 \pm 0.06$ \\
\hline 308.15 & $15.3 \pm 0.8$ & & $-2.43 \pm 0.07$ & $-15.385 \pm 0.007$ & $12.96 \pm 0.07$ \\
\hline 318.15 & $15.8 \pm 0.8$ & & $-6.6 \pm 0.1$ & $-15.738 \pm 0.008$ & $9.1 \pm 0.1$ \\
\hline \multicolumn{6}{|c|}{$\left[\mathrm{C}_{12} \mathrm{mim}\right] \mathrm{Br}$} \\
\hline 278.15 & $11.0 \pm 0.5$ & & $5.4 \pm 0.1$ & $-15.65 \pm 0.01$ & $21.1 \pm 0.1$ \\
\hline 288.15 & $10.5 \pm 0.5$ & & $1.45 \pm 0.08$ & $-16.34 \pm 0.01$ & $17.79 \pm 0.08$ \\
\hline 298.15 & $\begin{array}{c}10.7 \pm 0.5 \\
10.29^{\mathrm{c}} \\
9.07^{\mathrm{f}} \\
10.24^{\mathrm{g}} \\
9.68 \pm 0.05^{\mathrm{h}}\end{array}$ & $0.30 \pm 0.01$ & $\begin{array}{l}-2.53 \pm 0.06 \\
-3.51 \pm 0.01^{h}\end{array}$ & $-16.88 \pm 0.01$ & $14.36 \pm 0.06$ \\
\hline 308.15 & $11.1 \pm 0.5$ & & $-6.51 \pm 0.08$ & $-17.30 \pm 0.01$ & $10.80 \pm 0.08$ \\
\hline 318.15 & $12.0 \pm 0.6$ & & $-10.5 \pm 0.1$ & $-17.59 \pm 0.01$ & $7.1 \pm 0.1$ \\
\hline \multicolumn{6}{|c|}{$\left[\mathrm{C}_{12} \mathrm{mim}\right] \mathrm{I}$} \\
\hline 278.15 & $4.6 \pm 0.3$ & & $-3.0 \pm 0.1$ & $-21.74 \pm 0.01$ & $18.8 \pm 0.1$ \\
\hline 288.15 & $4.8 \pm 0.3$ & & $-6.85 \pm 0.07$ & $-22.35 \pm 0.01$ & $15.50 \pm 0.07$ \\
\hline 298.15 & $\begin{array}{c}5.2 \pm 0.3 \\
5.19^{\mathrm{c}} \\
4.76^{\mathrm{f}} \\
4.12^{\mathrm{g}}\end{array}$ & $0.16 \pm 0.01$ & $-10.72 \pm 0.06$ & $-22.82 \pm 0.01$ & $12.10 \pm 0.06$ \\
\hline 308.15 & $5.6 \pm 0.3$ & & $-14.60 \pm 0.07$ & $-23.16 \pm 0.01$ & $8.57 \pm 0.07$ \\
\hline 318.15 & $6.8 \pm 0.4$ & & $-18.5 \pm 0.1$ & $-23.38 \pm 0.01$ & $4.9 \pm 0.1$ \\
\hline \multicolumn{6}{|c|}{$\left[\mathrm{C}_{12} \mathrm{mim}\right] \mathrm{OAc}$} \\
\hline
\end{tabular}




\begin{tabular}{|c|c|c|c|c|c|}
\hline 278.15 & $21.8 \pm 0.4$ & & $15.8 \pm 0.1$ & $-11.29 \pm 0.02$ & $27.1 \pm 0.01$ \\
\hline 288.15 & $19.0 \pm 0.3$ & & $11.01 \pm 0.07$ & $-12.17 \pm 0.02$ & $23.19 \pm 0.07$ \\
\hline 298.15 & $\begin{array}{c}17.52 \pm 0.3 \\
17.27^{\mathrm{c}}\end{array}$ & $0.53 \pm 0.01$ & $6.25 \pm 0.05$ & $-12.90 \pm 0.02$ & $19.15 \pm 0.05$ \\
\hline 308.15 & $16.9 \pm 0.3$ & & $1.49 \pm 0.07$ & $-13.46 \pm 0.02$ & $14.95 \pm 0.07$ \\
\hline 318.15 & $16.9 \pm 0.3$ & & $-3.3 \pm 0.1$ & $-13.87 \pm 0.02$ & $10.6 \pm 0.1$ \\
\hline \multicolumn{6}{|c|}{$\left[\mathrm{C}_{12} \mathrm{mim}\right] \mathrm{OMs}$} \\
\hline 278.15 & $18.5 \pm 0.9$ & & $12.10 \pm 0.08$ & $-12.10 \pm 0.01$ & $24.20 \pm 0.08$ \\
\hline 288.15 & $16.7 \pm 0.9$ & & $7.80 \pm 0.07$ & $-12.91 \pm 0.01$ & $20.71 \pm 0.07$ \\
\hline 298.15 & $\begin{array}{c}15.7 \pm 0.8 \\
14.71^{\mathrm{c}} \\
12.50^{\mathrm{f}} \\
15.26^{\mathrm{g}}\end{array}$ & $0.55 \pm 0.01$ & $3.50 \pm 0.08$ & $-13.55 \pm 0.01$ & $17.05 \pm 0.08$ \\
\hline 308.15 & $15.6 \pm 0.8$ & & $-0.8 \pm 0.1$ & $-14.05 \pm 0.01$ & $13.3 \pm 0.1$ \\
\hline 318.15 & $16.0 \pm 0.8$ & & $-5.1 \pm 0.1$ & $-14.41 \pm 0.01$ & $9.3 \pm 0.1$ \\
\hline \multicolumn{6}{|c|}{$\left[\mathrm{C}_{12} \mathrm{mim}\right] \mathrm{OTs}$} \\
\hline 278.15 & $2.93 \pm 0.09$ & & $7.6 \pm 0.1$ & $-24.05 \pm 0.02$ & $31.6 \pm 0.1$ \\
\hline 288.15 & $2.83 \pm 0.09$ & & $1.36 \pm 0.07$ & $-25.08 \pm 0.02$ & $26.44 \pm 0.07$ \\
\hline 298.15 & $\begin{array}{c}2.88 \pm 0.09 \\
3.44^{\mathrm{c}} \\
2.25^{\mathrm{f}}\end{array}$ & $0.11 \pm 0.01$ & $-4.86 \pm 0.06$ & $-25.89 \pm 0.02$ & $21.03 \pm 0.06$ \\
\hline 308.15 & $3.04 \pm 0.09$ & & $-11.07 \pm 0.07$ & $-26.49 \pm 0.02$ & $15.42 \pm 0.07$ \\
\hline 318.15 & $3.31 \pm 0.09$ & & $-17.3 \pm 0.1$ & $-29.89 \pm 0.02$ & $9.6- \pm 0.1$ \\
\hline \multicolumn{6}{|c|}{$\left[\mathrm{C}_{12} \mathrm{mim}\right]$ OTf } \\
\hline 278.15 & $2.79 \pm 0.09$ & & $4.1 \pm 0.1$ & $-21.31 \pm 0.01$ & $25.4 \pm 0.1$ \\
\hline 288.15 & $2.76 \pm 0.08$ & & $-0.84 \pm 0.06$ & $-22.14 \pm 0.01$ & $21.30 \pm 0.06$ \\
\hline 298.15 & $\begin{array}{c}2.83 \pm 0.08 \\
2.71^{\mathrm{c}} \\
2.37^{\mathrm{f}} \\
2.69^{\mathrm{g}}\end{array}$ & $0.23 \pm 0.01$ & $-5.78 \pm 0.04$ & $-22.79 \pm 0.01$ & $17.02 \pm 0.04$ \\
\hline 308.15 & $3.01 \pm 0.09$ & & $-10.71 \pm 0.06$ & $-23.28 \pm 0.01$ & $12.57 \pm 0.06$ \\
\hline 318.15 & $3.30 \pm 0.09$ & & $-15.7 \pm 0.1$ & $-23.61 \pm 0.01$ & $8.0 \pm 0.1$ \\
\hline \multicolumn{6}{|c|}{$\left[\mathrm{C}_{12} \mathrm{mim}\right] \mathrm{TFA}$} \\
\hline 278.15 & $7.3 \pm 0.3$ & & $11.8 \pm 0.1$ & $-16.61 \pm 0.01$ & $28.4 \pm 0.1$ \\
\hline 288.15 & $6.7 \pm 0.3$ & & $6.56 \pm 0.06$ & $-17.54 \pm 0.01$ & $24.09 \pm 0.06$ \\
\hline 298.15 & $\begin{array}{c}6.5 \pm 0.3 \\
6.61^{\mathrm{c}} \\
5.23^{\mathrm{f}} \\
7.20^{\mathrm{g}}\end{array}$ & $0.44 \pm 0.01$ & $1.28 \pm 0.05$ & $-18.28 \pm 0.01$ & $19.56 \pm 0.05$ \\
\hline 308.15 & $6.5 \pm 0.3$ & & $-3.99 \pm 0.06$ & $-18.85 \pm 0.01$ & $14.86 \pm 0.06$ \\
\hline 318.15 & $6.9 \pm 0.03$ & & $-9.3 \pm 0.1$ & $-19.25 \pm 0.01$ & $10.0 \pm 0.1$ \\
\hline \multicolumn{6}{|c|}{$\left[\mathrm{C}_{12} \mathrm{mim}\right]$ Sal } \\
\hline 278.15 & $1.64 \pm 0.09$ & & $-2.6 \pm 0.1$ & $-26.22 \pm 0.03$ & $23.6 \pm 0.1$ \\
\hline 288.15 & $1.71 \pm 0.09$ & & $-7.89 \pm 0.07$ & $-26.97 \pm 0.03$ & $19.08 \pm 0.08$ \\
\hline
\end{tabular}




\begin{tabular}{|c|c|c|c|c|c|}
\hline 298.15 & $\begin{array}{c}1.83 \pm 0.09 \\
1.89^{\mathrm{c}} \\
1.59^{\mathrm{f}}\end{array}$ & $0.08 \pm 0.01$ & $-13.15 \pm 0.05$ & $-27.54 \pm 0.04$ & $14.39 \pm 0.06$ \\
\hline 308.15 & $2.04 \pm 0.09$ & & $-18.41 \pm 0.07$ & $-27.94 \pm 0.04$ & $9.52 \pm 0.08$ \\
\hline 318.15 & $2.33 \pm 0.09$ & & $-23.7 \pm 0.1$ & $-28.16 \pm 0.04$ & $4.5 \pm 0.1$ \\
\hline \multicolumn{6}{|c|}{$\left[\mathrm{C}_{14} \mathrm{mim}\right] \mathrm{Cl}$} \\
\hline 278.15 & $4.1 \pm 0.2$ & & $10.25 \pm 0.08$ & $-19.025 \pm 0.003$ & $29.28 \pm 0.08$ \\
\hline 288.15 & $3.8 \pm 0.2$ & & $5.09 \pm 0.05$ & $-19.985 \pm 0.002$ & $25.07 \pm 0.05$ \\
\hline 298.15 & $\begin{array}{c}3.7 \pm 0.2 \\
3.40 \pm 0.07^{\mathrm{d}} \\
3.45^{\mathrm{e}}\end{array}$ & $\begin{array}{c}0.386 \pm \\
0.008\end{array}$ & $\begin{array}{c}-0.08 \pm 0.04 \\
-0.5 \pm 0.3^{\mathrm{d}}\end{array}$ & $-20.767 \pm 0.001$ & $20.69 \pm 0.04$ \\
\hline 308.15 & $3.8 \pm 0.2$ & & $-5.24 \pm 0.05$ & $-21.375 \pm 0.002$ & $16.13 \pm 0.05$ \\
\hline 318.15 & $4.1 \pm 0.2$ & & $-10.41 \pm 0.08$ & $-21.816 \pm 0.004$ & $11.41 \pm 0.08$ \\
\hline \multicolumn{6}{|c|}{$\left[\mathrm{C}_{16} \mathrm{mim}\right] \mathrm{Cl}$} \\
\hline 288.15 & $0.93 \pm 0.05$ & & $3.04 \pm 0.08$ & $-24.81 \pm 0.04$ & $27.85 \pm 0.08$ \\
\hline 298.15 & $\begin{array}{c}0.93 \pm 0.05 \\
0.99^{\mathrm{e}}\end{array}$ & $0.42 \pm 0.01$ & $-3.04 \pm 0.07$ & $-25.67 \pm 0.04$ & $22.63 \pm 0.08$ \\
\hline 308.15 & $0.98 \pm 0.05$ & & $-9.13 \pm 0.08$ & $-26.33 \pm 0.04$ & $17.20 \pm 0.09$ \\
\hline 318.15 & $1.07 \pm 0.05$ & & $-15.21 \pm 0.09$ & $-26.79 \pm 0.05$ & $11.6 \pm 0.1$ \\
\hline
\end{tabular}

${ }^{\mathrm{a}}$ Units: cmc, mmol kg${ }^{-1} ; \Delta_{\mathrm{M}} H^{0}, \Delta_{\mathrm{M}} G^{0}, T \Delta_{\mathrm{M}} S^{0}, \mathrm{~kJ} \cdot \mathrm{mol}^{-1}$.

${ }^{\mathrm{b}}$ The reported errors correspond to the precision of the experimental data and the fitting procedure assuming the proposed model is correct.

${ }^{\mathrm{c}}$ From conductivity measurements, some values are taken from ref. [11]

${ }^{\mathrm{d}}$ ref, [12]

eref. [13]

${ }^{\mathrm{f}}$ From surface tension measurements, some values are taken from ref. [11]

${ }^{\mathrm{g}}$ From UV-Vis spectroscopy in ref. [11]

$\mathrm{d}{ }^{\mathrm{h}}$ ref. [14] 
Table S2. Coefficients of polynomials $c m c=\mathrm{A}+\mathrm{B} T+\mathrm{C} T^{2 a}$.

\begin{tabular}{l|ccc}
\hline & $\mathrm{A}$ & $\mathrm{B}$ & $10^{3} \cdot \mathrm{C}$ \\
\hline$\left[\mathrm{C}_{10} \mathrm{mim}\right] \mathrm{Cl}$ & 1152.27 & -7.08185 & 11.46 \\
{$\left[\mathrm{C}_{12} \mathrm{mim}\right] \mathrm{Cl}$} & 286.4849 & -1.79154 & 2.9570 \\
{$\left[\mathrm{C}_{12} \mathrm{mim}\right] \mathrm{Br}$} & 189.4947 & -1.22603 & 2.1000 \\
{$\left[\mathrm{C}_{12} \mathrm{mim}\right] \mathrm{I}$} & 59.14728 & -0.40257 & 0.74286 \\
{$\left[\mathrm{C}_{12} \mathrm{mim}\right] \mathrm{OAc}$} & 463.1606 & -2.87050 & 4.6143 \\
{$\left[\mathrm{C}_{12} \mathrm{mim}\right] \mathrm{OMs}$} & 370.868 & -2.32198 & 3.7929 \\
{$\left[\mathrm{C}_{12} \mathrm{mim}\right] \mathrm{OTs}$} & 53.95552 & -0.35234 & 0.60714 \\
{$\left[\mathrm{C}_{12} \mathrm{mim}\right] \mathrm{OTf}$} & 46.66583 & -0.30675 & 0.53571 \\
{$\left[\mathrm{C}_{12} \mathrm{mim}\right] \mathrm{TFA}$} & 147.1805 & -0.93416 & 1.5500 \\
{$\left[\mathrm{C}_{12} \mathrm{mim}\right] \mathrm{Sal}$} & 30.38843 & -0.20864 & 0.37857 \\
{$\left[\mathrm{C}_{14} \mathrm{mim}\right] \mathrm{Cl}$} & 79.62678 & -0.51011 & 0.85714 \\
{$\left[\mathrm{C}_{16} \mathrm{mim}\right] \mathrm{Cl}$} & 20.20205 & -0.13172 & 0.22500 \\
\hline
\end{tabular}

${ }^{\mathrm{a}}$ Units: $T / \mathrm{K} ; \mathrm{A} / \mathrm{mmol} \mathrm{kg}^{-1}, \mathrm{~B} / \mathrm{mmol} \mathrm{kg}^{-1} \cdot \mathrm{K}^{-1} ; \mathrm{C} / \mathrm{mmol} \mathrm{kg}^{-1} \cdot \mathrm{K}^{-2}$ 


\section{References}

[1] J. N. Phillips, The energetics of micelle formation, J. Trans Soc. 51 (1955) 561-569.

[2] R. J. Hunter, Foundations of Colloid Science, Vol. 1, Clarendon Press, Oxford, 1987.

[3] J. Lah, C. Pohar, G. Vesnaver, Calorimetric Study of the Micellization of Alkylpyridinium and Alkyltrimethylammonium Bromides in Water, J. Phys. Chem. B 104 (2000) 2522-2526.

[4] J. Lah, M. Bešter-Rogač, T.-M. Perger, G. Vesnaver, Energetics in Correlation with Structural Features: The Case of Micellization, J. Phys. Chem. B 110 (2006) 23279-23291.

[5] E. M. Woolley, T. E. Burchfield, Model for Thermodynamics of Ionic Surfactant Solutions. 2. Enthalpies, Heat Capacities, and Volumes, J. Phys. Chem. 88 (1984) 21552163.

[6] W. H. Press, B. P. Flannery, S. A. Teukolsky, W. T. Vetterling, Numerical Recipes, Cambridge University Press, Oxford, 1992, p 650.

[7] D. Hallen, Data treatment: Considerations when applying binding reaction data to a model, Pure Appl. Chem. 65 (1993) 1527-1532.

[8] S. A., Vetterling, W. T. 1992 Numerical Recipies, Cambridge University Press, Oxford, pp. 650-694.

[9] I. Drobnak, G. Vesnaver, J. Lah, J. Model-Based Thermodynamic Analysis of Reversible Unfolding Processes, J. Phys. Chem. B 114 (2010) 8713-8722.

[10] A. Kroflič, B. Šarac,M. Bešter-Rogač, Thermodynamic Characterization of CHAPS Micellization Using Isothermal Titration Calorimetry: Temperature, Salt, and $\mathrm{pH}$ Dependence, Langmuir 28 (2012) 10363-10371.

[11] A. Cognigni, P. Gärtner, R. Zirbs, H. Peterlik, K. Prochazka, C. Schröder, K. Bica, Surface-active ionic liquids in micellar catalysis: impact of anion selection on reaction rates in nucleophilic substitutions, Phys. Chem. Chem. Phys. 18 (2016) 13375- 13384.

[12] J. Łuczak, C. Jungnickel, M. Joskowska, J. Thöming, J. Hupka, Thermodynamics of micellization of imidazolium ionic liquids in aqueous solutions, J. Colloid. Interface Sci. 336 (2009) 111-116.

[13] P. D Galgano, O. A. El Seoud, Surface active ionic liquids: Study of the micellar properties of 1-1-alkyl]-3-methylimidazolium chlorides and comparison with structurally related surfactants, J. Colloid. Interface. Sci. 361 (2011) 186-194.

[14] F. Geng, J. Liu, L. Zheng, L. Yu, Z. Li, G. Li, C. Tung, Micelle formation of long-chain imidazolium ionic liquids in aqueous solution measured by isothermal titration microcalorimetry, J. Chem. Eng. Data. 55 (2010) 147-51. 